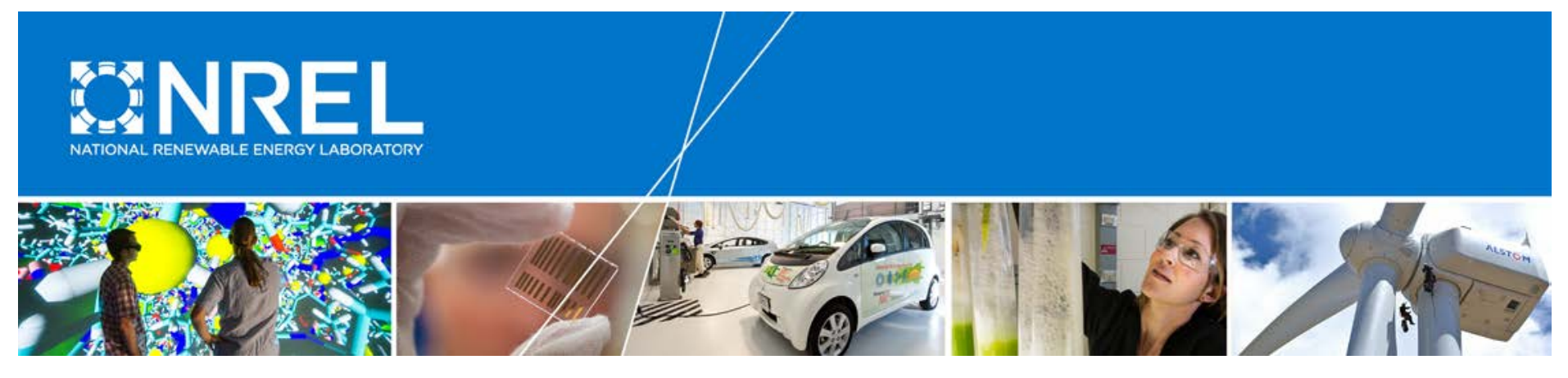

\title{
The Flexible Solar Utility: Preparing for Solar's Impacts to Utility Planning and Operations
}

John Sterling and Ted Davidovich Solar Electric Power Association

Karlynn Cory, Alexandra Aznar, and Joyce McLaren

National Renewable Energy Laboratory (NREL)

NREL is a national laboratory of the U.S. Department of Energy Office of Energy Efficiency \& Renewable Energy Operated by the Alliance for Sustainable Energy, LLC

This report is available at no cost from the National Renewable Energy Laboratory (NREL) at www.nrel.gov/publications.

Technical Report

NREL/TP-6A20-64586

September 2015 


\section{The Flexible Solar Utility: Preparing for Solar's Impacts to Utility Planning and Operations}

John Sterling and Ted Davidovich Solar Electric Power Association

Karlynn Cory, Alexandra Aznar, and Joyce McLaren

National Renewable Energy Laboratory (NREL)

Prepared under Task No. SM13.1570

NREL is a national laboratory of the U.S. Department of Energy Office of Energy Efficiency \& Renewable Energy Operated by the Alliance for Sustainable Energy, LLC

This report is available at no cost from the National Renewable Energy Laboratory (NREL) at www.nrel.gov/publications.

National Renewable Energy Laboratory 15013 Denver West Parkway Golden, CO 80401

303-275-3000 • www.nrel.gov

\section{Technical Report}

NREL/TP-6A20-64586

September 2015

Contract No. DE-AC36-08GO28308 


\title{
NOTICE
}

This report was prepared as an account of work sponsored by an agency of the United States government. Neither the United States government nor any agency thereof, nor any of their employees, makes any warranty, express or implied, or assumes any legal liability or responsibility for the accuracy, completeness, or usefulness of any information, apparatus, product, or process disclosed, or represents that its use would not infringe privately owned rights. Reference herein to any specific commercial product, process, or service by trade name, trademark, manufacturer, or otherwise does not necessarily constitute or imply its endorsement, recommendation, or favoring by the United States government or any agency thereof. The views and opinions of authors expressed herein do not necessarily state or reflect those of the United States government or any agency thereof.

This report is available at no cost from the National Renewable Energy Laboratory (NREL) at www.nrel.gov/publications.

Available electronically at SciTech Connect http:/www.osti.gov/scitech

Available for a processing fee to U.S. Department of Energy and its contractors, in paper, from:

\author{
U.S. Department of Energy \\ Office of Scientific and Technical Information \\ P.O. Box 62 \\ Oak Ridge, TN 37831-0062 \\ OSTI http://www.osti.gov \\ Phone: 865.576.8401 \\ Fax: 865.576.5728 \\ Email: reports@osti.gov
}

Available for sale to the public, in paper, from:

\author{
U.S. Department of Commerce \\ National Technical Information Service \\ 5301 Shawnee Road \\ Alexandria, VA 22312 \\ NTIS http://www.ntis.gov \\ Phone: 800.553 .6847 or 703.605 .6000 \\ Fax: 703.605.6900 \\ Email: orders@ntis.gov
}




\section{Acknowledgments}

This paper was prepared by the National Renewable Energy Laboratory (NREL) and the Solar Electric Power Association (SEPA), who worked together to engage utilities directly to research solar in long-term utility planning and author this report. NREL managed the project, directed research, and led analysis of results. NREL is a national laboratory of the U.S. Department of Energy Office of Energy Efficiency \& Renewable Energy Operated by the Alliance for Sustainable Energy, LLC. SEPA is a 501 (c)(3) educational non-profit research organization that delivers the latest actionable information to help members (utilities, developers, manufacturers, and installers) implement solar business plans, get smarter about the changing energy sector, meet peers, and exchange ideas.

NREL and SEPA would like to thank the following individuals and companies for providing valuable input, insights, and feedback throughout this project: John Pang and Paul Quinlan (ScottMadden Management Consultants); Daniel Kassis (SCE\&G); Carmine Tilghman (Tucson Electric Power); Olusola Akinmeji; Jason Thackston (Avista); Laura Williams (Madison Gas \& Electric); and Elizabeth Doris, David Hurlbut, Margaret Mann, Emerson Reiter, and Jenny Heeter (NREL). The authors would also like to thank the attendees of our working session at the Utility Solar Conference and additional contributors who choose to remain anonymous.

NREL would also like to thank the team that developed and refined the Electric Systems of the Future framework that laid the foundation for a portion of this analysis (in the Appendices), including Michael Coddington, Michael Milligan, Mark Ruth, and Adam Warren (NREL), as well as NREL colleagues that commented and contributed to the framework development (Kristen Ardani, Sonja Berdahl, Lori Bird, Debbie Brodt-Giles, Nancy Carlisle, Jaquelin Cochran, Paul Denholm, Dick DeBlasio, Elizabeth Doris, Michael Elchinger, David Hurlbut, Marguerite Kelly, Joyce McLaren, Mackay Miller, Robin Newmark, Brett Oakleaf, Bryan Palmintier, Gian Porro, Brent Rice, Paul Schwabe, Greg Stark, and Andy Walker). The authors are also grateful to our eight external advisors, who were promised anonymity.

We would also like to thank the many utility industry individuals we interviewed or that answered our questionnaire. Finally, we would like to thank our project sponsors, the Solar Energy Technologies Office - Soft Cost Program at the U.S. Department of Energy. 


\section{Table of Contents}

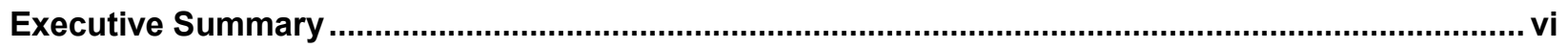

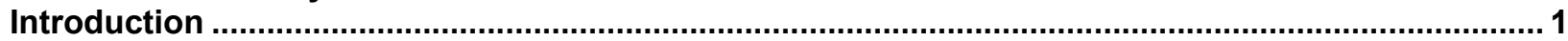

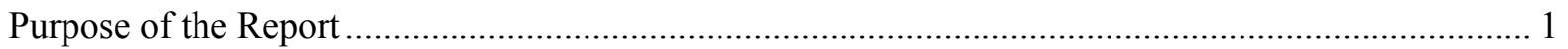

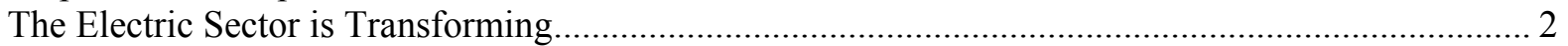

Other Activities Evaluating Changes to the Electric Sector.......................................................2 2

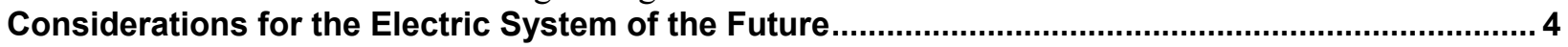

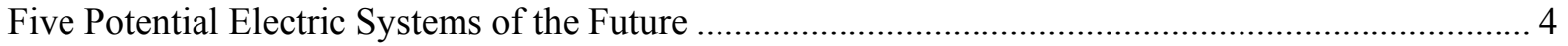

Electric System Futures - Emerging Disruptions......................................................................... 5

Understanding Rapid DER Growth on Utility Business Functions............................................... 7

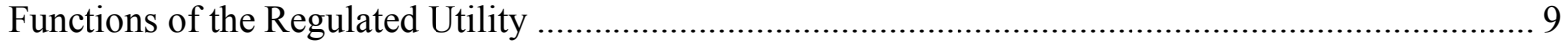

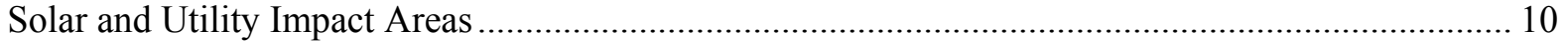

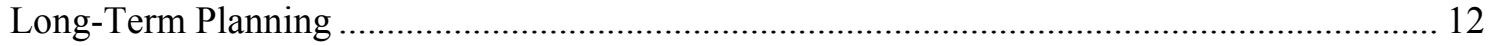

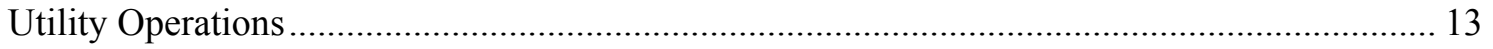

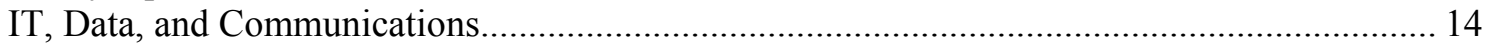

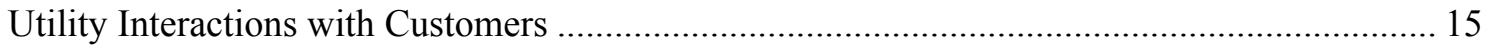

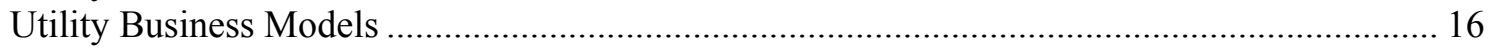

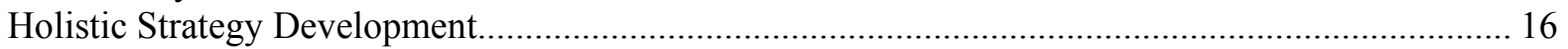

Planning and Operations - Realizing Tomorrow's Requirements Today ......................................... 18

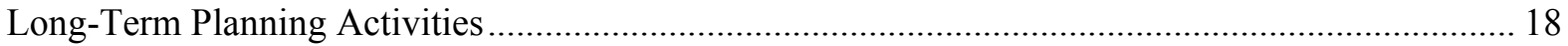

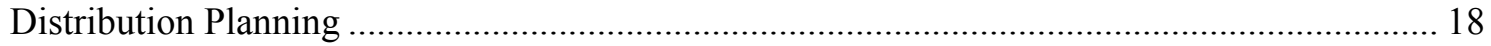

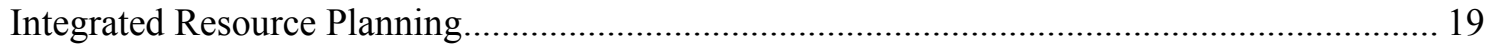

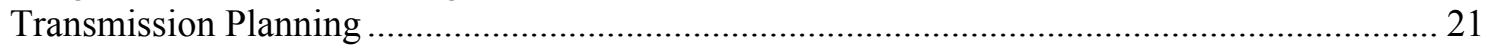

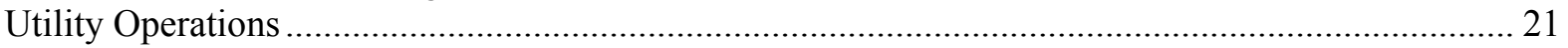

Creating the Flexible Utility: Roadmaps and Signposts to the Future ............................................. 25

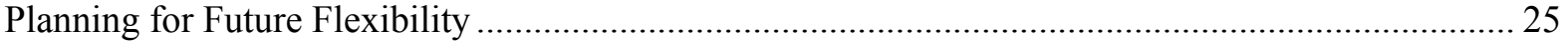

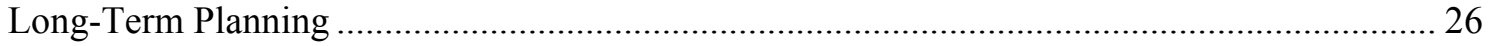

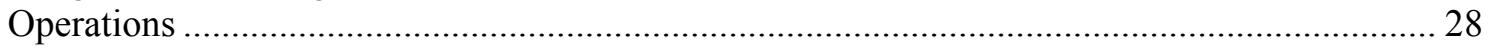

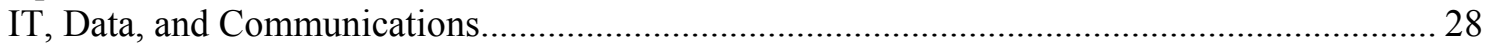

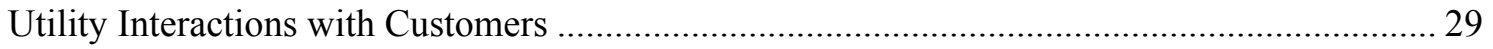

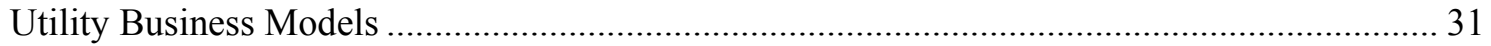

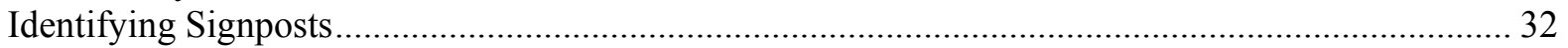

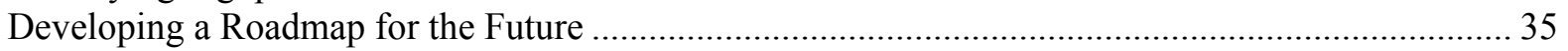

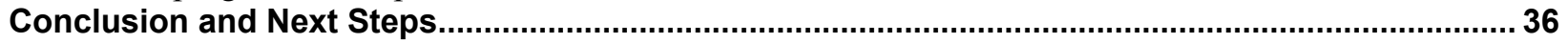

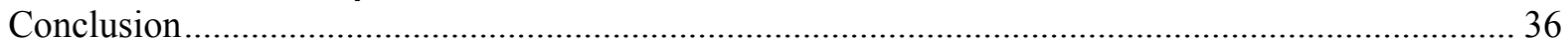

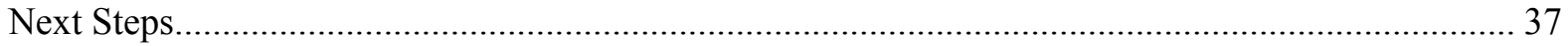

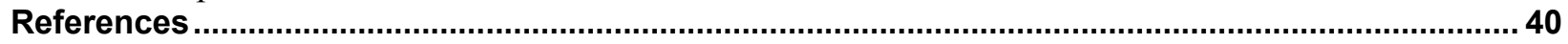

Appendix A. Electric Systems of the Future - Descriptions ..........................................................45

Appendix B. Summary of Emerging Disruptions and How They Map to Potential Futures............... 46

Appendix C. Key Enablers and Barriers for Three Main Future Directions ......................................47

Bibliography: Other Activities Evaluating Changes to the Electric Sector ......................................51 


\section{List of Tables}

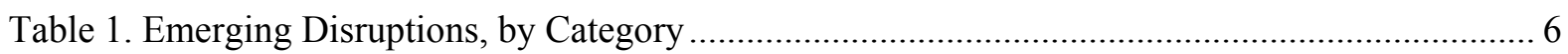

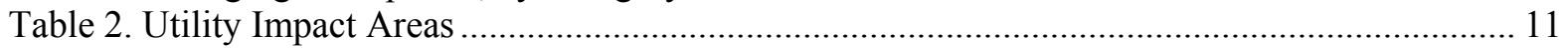

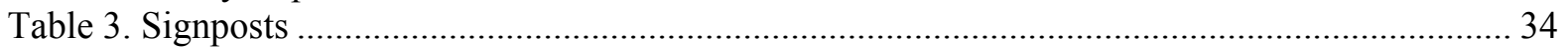

Table A-1. Electricity Systems of the Future: Five Directions ....................................................... 45

Table C-1. Description of the Evolution of Each Future, Identifying Key Enablers and Barriers....... 50

\section{List of Figures}

Figure ES-1. Solar and utility impact areas............................................................................... vii

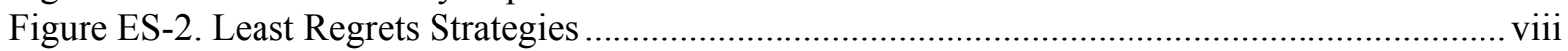

Figure ES-3. Steps to becoming a flexible utility........................................................................ viii

Figure 1. The continuum of pathways to support increased decentralization requires increased

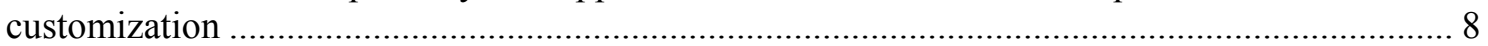

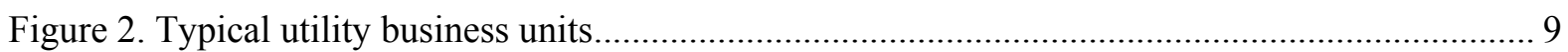

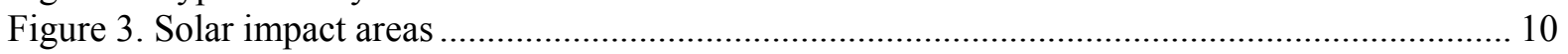

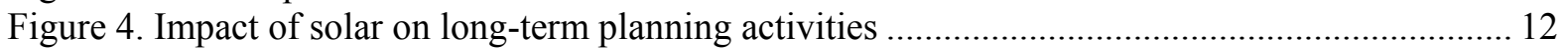

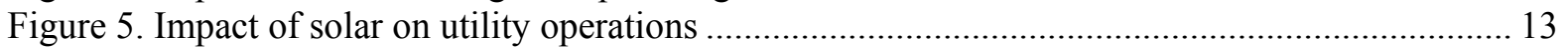

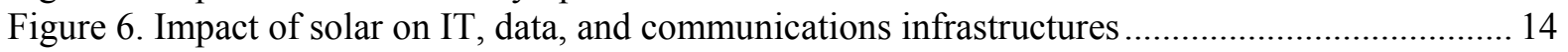

Figure 7. Impact of solar on utility interactions with customers ................................................ 15

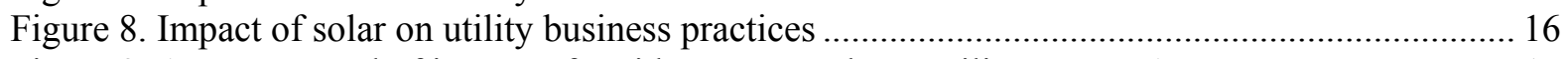

Figure 9. Average Level of impact of rapid DER growth on Utility Impact Areas ........................... 17

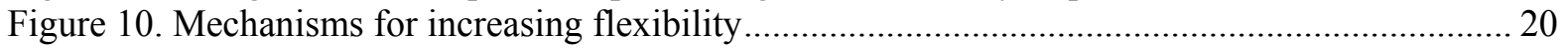

Figure 11. Integration of planning and operations across the flexible solar utility ............................ 24

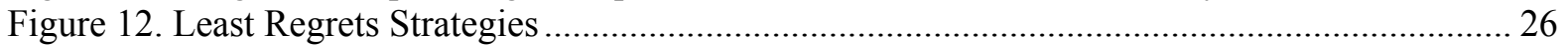

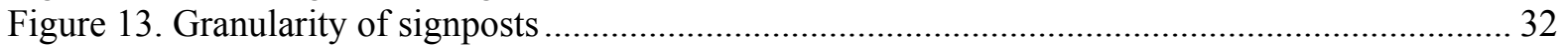

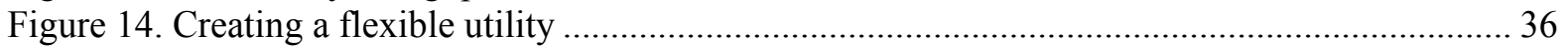

Figure B-1. Summary of emerging disruptions and how they map to potential futures...................... 46

Figure C-1. Key enablers and barriers for three main future directions (the earlier years) .................47

Figure C-2. Key enablers and barriers for three main future directions (the later years) .................... 48 


\section{Executive Summary}

Solar growth and the emergence of new technologies are changing electric utilities going forward; variable renewables are spreading in the United States, distributed energy resources (DER) are being embraced by end-users, and there is a lot of discussion about increasing interactivity of the grid - both by creating linkages between transmission and distribution, as well as between customers and their utilities. Although not every utility, region, or market will change in the same way or magnitude, developing a planned path forward will help each region to reach its "optimal" system. Complicating this process is a series of emerging disruptions, decisions, or events that will likely cause and accelerate electric sector change. Understanding and preparing for these potential disruptions can help utilities plan for and, at least partially, influence this future transformation. Predicting what the future of the electricity system will look like 10 years from now is difficult; however, utilities still can look ahead and try to anticipate and prepare for a variety of changes that are likely to impact their planning, operations, and business models.

The goal of this report is to identify ways the utility can proactively prepare for solar growth on their system (particularly DER), while maintaining a successful utility business. In order to understand some of the biggest challenges and potential transformations to the conventional utility business model, the authors focused this analysis on a scenario with rapid adoption of DER in the future. ${ }^{1}$ Rapid growth of DER will likely create some of the biggest challenges to the conventional utility business model. The authors conducted a series of utility interviews, held a working session at a major industry solar conference, and conducted a quantitative survey specifically on distributed solar. Distributed solar could serve as a proxy resource for all distributed generation (DG); it can also provide the foundation for all DERs. As shown in Figure ES-1, the distributed solar impact was broken down into five main themes, each of which was considered across fifteen different utility functions to determine where and how utilities may need to adjust in a future with rapid DER growth.

\footnotetext{
${ }^{1}$ Change can also come from addition of 1 . more low-carbon, centralized generation, 2 . increased interactivity of the transmission and distribution grid, as well as utility-customer interactions, and 3. grid defection. Rapid growth of DER was emphasized in this report.
} 


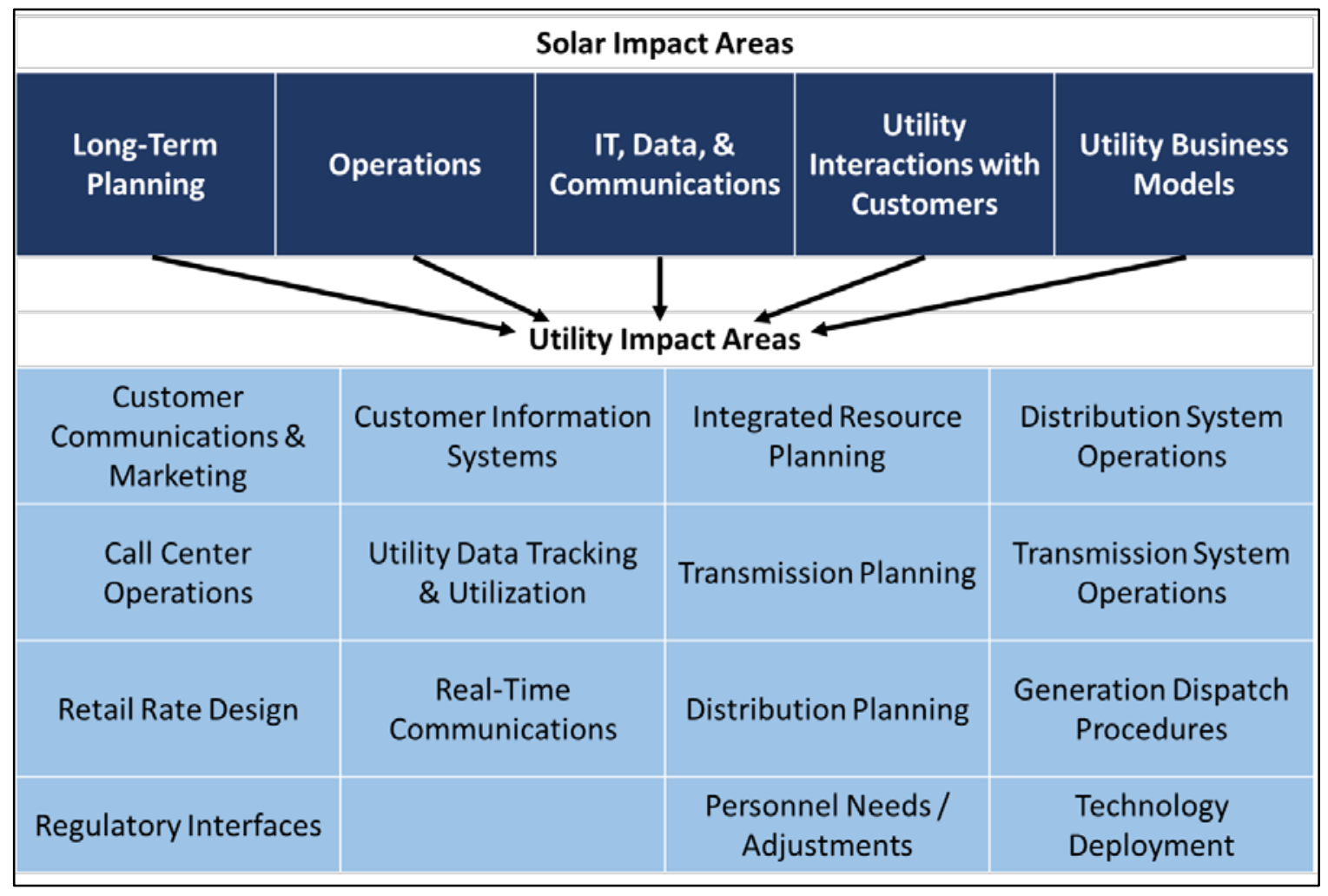

Figure ES-1. Solar and utility impact areas

Utilities interviewed identified safe, reliable, and cost-effective service in a rapid DER growth future to be critical for a successful evolution. From these and other suggestions, the authors identified a series of "Least Regrets Strategies" (see Figure ES-2) which identify potential incremental changes for how utilities plan for and operate the system and how they interact with consumers; the strategies are expected to prepare the utility for a future where distributed solar generation is pervasive. Taken in whole or in part, these activities can be leveraged to better prepare the utility for future changes. 
- Develop supply- and demand-based distribution plans that roll up into the integrated resource plan (IRP)

-Treat DERs as both fixed inputs and as selectable resources in the IRP

-Integrate Supply, Demand, Transmission, and Distribution planning processes into an overarching process

-Discuss a long-term distribution system investment plan with regulators

Operations

-Update standard equipment list to support distribution integration needs and infrastructure requirements

-Deploy advanced inverters system-wide

-Deploy sub-meters for distributed generation resources

\section{IT, Data, \& Communications}

-Develop a long-term IT, data, and communications plan that is tied into other planning processes

-Strategically deploy real-time communications infrastructure, AMI, etc.

- Move towards automated data management and analytics

Utility Interactions with Customers

- Create a "green team" for the customer call center

-Enable sophisticated customer energy portals

- Investigate new rate and pricing models

- Create routine customer workshops on energy consumption, new in-home technologies, and other topics of interest

\section{Utility Business Models}

-Move towards holistic customer program design

- Create employee training initiatives around the changing grid

-Balance rate cases with multi-year rate reform plans

Figure ES-2. Least Regrets Strategies

There are specific signposts - metrics, trends, and activities - that may signal when and how fast the rapid DER growth future is approaching. These signposts range from broad (e.g., industry trends) to the localized (e.g., utility metrics) to the specific (e.g., customer activities). By focusing on these signposts and identifying the Least Regrets Strategies that best align with a utility's core capabilities and desires, a utility company can introduce a level of flexibility into their planning and operations today so that they can proactively adjust to a variety of future directions, as shown in Figure ES-3. This added flexibility should translate into less risk to the core business over the long term. Specifically, utilities might want to:
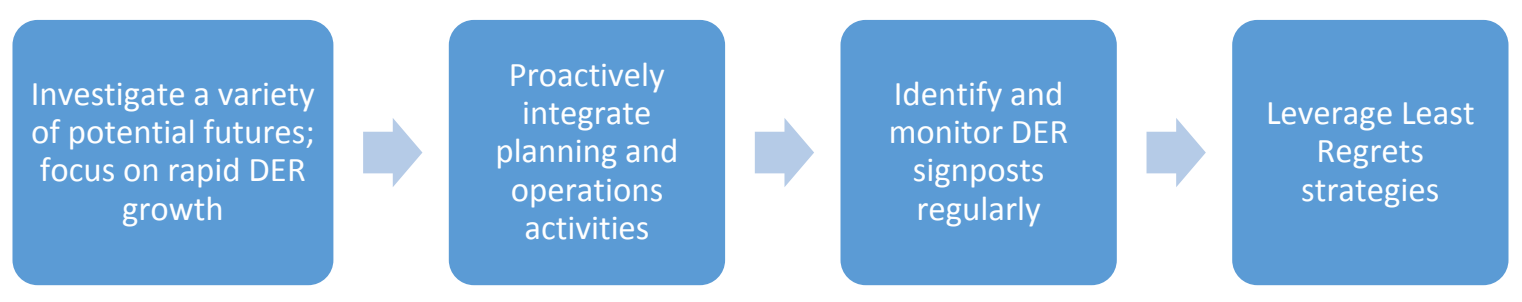

Figure ES-3. Steps to becoming a flexible utility 


\section{Introduction}

\section{Purpose of the Report}

The accelerated deployment of utility-scale solar technologies and distributed generation (DG) has potentially significant implications for both the future of the U.S. electric system and utility roles and functions. Key questions include:

- How can utilities respond to a future affected by solar expansion?

- What impacts will solar have on utility planning activities?

$\circ$ How can large scale and distributed solar generation be planned into the existing system?

- How will solar impact utility operations?

- Who will control/operate the solar generation, particularly DG?

$\circ$ How will large scale and distributed generation be integrated into the existing system?

- How does solar impact information technologies (IT), data, and communications needs?

- Will solar impact utility interactions with customers?

- Who will own the solar - the customer, the utility, or a combination?

- How will solar impact utility business models and how does the utility secure enough revenue to remain a viable business?

Incorporating solar considerations now into utility planning and operations can help utilities anticipate and proactively mold solar interactions, as well as solar transformations in the whole electric system, rather than just react.

The goal of this report is to identify ways the utility can proactively prepare for solar growth on their system (particularly DER), while maintaining a successful utility business. This report seeks to inform investor-owned utilities (IOUs) ${ }^{2}$ and regulators about how utilities can respond to increasing amounts of DERs (particularly distributed solar) so they are best positioned to succeed across a variety of future states by:

1. Conveying how the future could look depending on how certain key variables and uncertainties unfold

2. Identifying the wide variety of functional areas, roles, responsibilities within a utility that are affected by solar and these future states

3. Conducting a deep dive on two key functional areas - Planning and Operations - to understand utility methods and how they may need to change

4. Discussing how flexibility and planning can be built into today's decision making process to provide higher likelihood of future success (i.e., a Least Regrets Strategy)

5. Identifying key signposts that could indicate the scale and scope of potential changes and conditions under which a utility may reconsider actions and potentially change course.

\footnotetext{
${ }^{2}$ While this report focuses on IOUs, many aspects are relevant to municipal utilities and rural electric cooperatives as well.
} 


\section{The Electric Sector is Transforming}

Widespread geographic participation in distributed solar and other DERs has the potential to change the utility industry dramatically. To the extent that federal and state regulators continue to support solar industry growth and customers continue to demand solar options, it will be important to examine how solar is treated in rates and in utility business models. This report tries to envision potential pathways where utilities can play an active role in proactive planning and operational changes in order to maintain the utility's viability as a business, while potentially supporting continued growth of solar and other DERs.

In most U.S. markets, regulators and utilities are critical for determining the ease, cost of, and compensation for integrating a transformative amount of solar power. If not done with full systems thinking, rate treatment and utility business models, operational practices, and programmatic offerings could slow solar deployment and market transformation. Furthermore, new technologies (e.g., storage) and the greater prevalence of advanced meters are starting to emerge; these supporting technologies could enable alternate rate designs, time-based pricing, increased customer-utility communications, and new utility business models.

As incentives for distributed solar decline in many parts of the country, the underlying rate structures and fees imposed by utilities take on increasing importance because they become the main influencer of customer decisions to employ PV. And whether utilities interconnect, integrate, own, contract with, or provide programs to support solar power (both PV and concentrating solar power [CSP]), concerns about recovering fixed system costs can impact individual project economics as well as the utility's ability to recover system costs that support solar integration. Collaboration across utilities, regulators, and technology developers is key to easing the transition to the future of the energy industry.

\section{Other Activities Evaluating Changes to the Electric Sector}

This paper builds on many other activities examining changes in the electric sector, and specifically on identifying actionable utility business models and rate design options that can address utility concerns while enabling accelerated solar deployment. See the bibliography at the end of the report for more details.

There are several examinations of the evolution of the electric sector as a whole across the globe (Zinaman et al. 2015; Satchwell 2015; SEPA 2014; CSIRO 2013; Richter 2013). And many analyses have examined the barriers and opportunities to high adoption of variable energy resources (Cory and Aznar 2014; Jones, ed. 2014; Cochran et al. 2014a; Blarke and Jenkins 2013; Hand et al 2012; Cochran et al. 2012; Forrest and Frantzis 2010), including bulk power system impacts of solar and wind energy (Bird and Milligan 2012; Porter et al. 2012), potential curtailment concerns (Bird et al. 2014), and solar financing (Mendelsohn et al. 2012). Several analyses considered the implications of the growth of DERs on utility business models (EPRI 2015; BNEF 2014; Kind 2013).

Many analyses are considering regulatory implications of different energy futures as well (Miller and Cox 2014; Zinaman et al. 2014; Aggarwal and Burgess 2014 and Lehr 2013), including specific activities in New York (NY DPS 2015) and Hawaii (HI PUC 2014). NREL is specifically using the System Advisor Model (SAM) to quantify the impacts of rate design on PV economics (McLaren et al. 2015) and regulatory options for incorporating solar (Bird et al. 
2013). Furthermore, previous NREL analyses have examined how to quantify the value of solar (Denholm et al. 2014), how to design "value of solar" tariffs (Taylor et al. 2015), and net metering policy best practices (Heeter et al. 2014). Finally, the U.S. Department of Energy (DOE) is creating a series of reports called "On the Path to SunShot," which are examining the mid-point for meeting the aggressive DOE goals for solar cost reductions and solar deployment. The relevant report is "Challenges and Opportunities Associated with Utility Regulatory and Business Model Reforms" (forthcoming).

Also on regulatory issues, rate design, and utility business models, other research has covered a wide range of considerations as to how the electric sector is changing. A full list of parallel initiatives, papers, and thought leadership (including citations) is provided at Appendix D. Other Activities Evaluating Changes to the Electric Sector. To summarize, these sources cover:

- Research on how electric systems may evolve internationally both in the developing world and in developed countries that have already witnessed shifts in their business-asusual electric paradigm, like Germany

- Envisioning what a specific country's electric system could look like after a shift (e.g., Australia)

- Growth of distributed energy resources and implications for traditional utility business models. A branch of this discussion focuses on grid or load defection - the idea that declining costs and widespread adoption of DER could enable customers to fulfill their own energy needs and "defect" from their electric utility.

- Investigating the technological barriers and opportunities for integrating large amounts of variable renewable energy generation onto the grid, with an eye towards the potential to decarbonize the electric sector in the face of global climate change

- New regulatory challenges as the electric system evolves, which have great potential to impact future direction. Regulators in Hawaii and New York, for example, are already reenvisioning electricity regulation in response to deployment of DER. 


\section{Considerations for the Electric System of the Future}

This section lays out an organized framework for thinking through potential planning and operational changes (among others) that utilities will likely face as resource mixes, policies, regulations, and market structures evolve. First, the authors identify five potential futures for the electricity system. Next, some of the key drivers that can enable these futures are highlighted. Finally, the analysis focuses on the rapid growth of DER as a future that may have the biggest impact on utility planning and operations, and then discuss the different functional areas within a utility that are impacted by solar deployment. Overlaying the potential electric system futures and utility functional areas provides insight into how utility operations and planning can adopt a Least Regrets Strategy when faced with an uncertain future.

From an organizational and technical perspective, utility-scale and distributed solar differ in requiring unique considerations from four main decision makers: consumers, power companies, policymakers, and investors. Utilities and policymakers actively advancing more renewable energy deployment can consider common ways to enable both utility-scale and distributed solar. Increased solar penetration will require increased flexibility requirements.

\section{Five Potential Electric Systems of the Future}

There are many possibilities for how the Electric System of the Future (ESF) may evolve - some can enable solar, and others will create opportunities for other smart grid or clean technologies. NREL analysts developed five distinct future scenarios based on existing literature and professional judgment. They were then vetted internally and in a workshop by a group of external advisors with utility and regulatory expertise. These scenarios were not predictions, but paradigms to help decision makers consider a number of different possibilities in order to test today's decisions against a variety of futures. The scenarios are useful when considering how the electric sector and utilities are changing and why they are changing, and to identify additional transformation avenues.

These five possible scenarios vary based on generation mix, flexibility mechanisms, investment decisions, transmission and distribution changes, and other technological, communication, and behavior characteristics. They include:

1. Business-as-Usual: no transformational updates; replacement of aging infrastructure with current standard versions

2. Low-Carbon, Centralized Generation: replacement of large, centralized, carbon-intensive generation with large, centralized, low-carbon or carbon-free generation

3. Rapid Growth of DERs: non-dispatchable distributed generation, distributed storage, and energy efficiency become common and widely adopted

4. Interactivity of the Grid and Demand: high interactivity between flexible, integrated, and optimized transmission and distribution, grid-level storage, dispatchable DERs, demand response, smart grid, and consumer demand

5. Grid or Load Defection: dramatic improvements in storage, cost reductions in distributed generation, and high energy costs lead to customer load defection (i.e., reduced demand from utilities) or customer grid defection (i.e., separating from utilities and self-supplying). 
Appendix A. Electric Systems of the Future provides descriptions of these five distinct future directions that electric systems could take in the next 20 years. The authors do not expect that the entire country, or even any particular region, would necessarily choose to emphasize the same future direction; defining them separately helps one understand the particular needs of emphasizing a particular future, identify key barriers and enablers that intersect in multiple futures, and understand how choices made today can leave open or shut off future options.

\section{Electric System Futures - Emerging Disruptions}

Emerging disruptions are decisions or events that will likely spark electric sector transformation and they are shown in Table 1. Five key areas will be critical for successful transformation to any future different than today: technology, policy and regulatory, market, financing, and utility business model considerations. Some disruptions touch more than one of these key areas. As more emerging disruptions occur, the electric system transforms faster and more thoroughly. Decision makers can proactively choose to enact most of the disruptions using policies and regulations. Through near-term actions (described later), decision makers can proactively shape the electric system evolution.

Each emerging disruption in Appendix B is aligned with the futures that could be most impacted by that disruption. Several disruptions may enable multiple futures. By identifying these relationships, it is easier to see which choices lead to which futures, and which do not enable or directly interact with others. There is a graphical representation of the relationships of the emerging disruptions and how they connect to the different potential future directions, shown in Appendix B. Summary of Emerging Disruptions and How They Map to Potential Futures.

The goal of this exercise is to identify the critical enablers and barriers that could result in one or a combination of multiple futures to materialize. More details about specific enablers, barriers, and their sequence for successfully enabling the three main future directions of interest is captured in Appendix C. Key Enablers and Barriers for Three Main Future Directions.

The Rapid DER future was chosen as a main emphasis for this report because a proliferation of small distributed energy resources across a utility's system could drastically impact utility planning and operations. The next three main sections constitute the main areas of research. The section titled Understanding rapid DER growth on Utility Business Functions identifies the areas where DG PV interact with overall utility business operations in a high-level way on all levels of the utility as a business. Interactions and impacts that solar (and DER) will likely have on the utility are identified. The next major section titled Planning and Operations - Realizing Tomorrow's Requirements Today is a deep dive into utility planning and operations specifically. This section explores specific changes that may be required to planning and operations to support DER, and especially solar PV, adoption. Finally, the last major section, Creating the Flexible Utility: Roadmaps and Signposts to the Future, identifies metrics to track and things to monitor and look out for and identifies Least Regrets Strategies that are expected to position most utilities to be ready for rapid growth of DER. The goal of this last section is to identify data collection and analysis activities that make sense now so that the utility can be prepared to proactively shape the future instead of just reacting to oncoming changes. 
Table 1. Emerging Disruptions, by Category

\begin{tabular}{|c|c|c|c|c|}
\hline & $\begin{array}{l}\text { Low-Carbon, } \\
\text { Centralized } \\
\text { Generation }\end{array}$ & $\begin{array}{l}\text { Rapid } \\
\text { Growth of } \\
\text { DER }\end{array}$ & $\begin{array}{l}\text { Interactivity } \\
\text { of the Grid } \\
\text { and Demand }\end{array}$ & $\begin{array}{l}\text { Grid or } \\
\text { Load } \\
\text { Defection }\end{array}$ \\
\hline \multicolumn{5}{|l|}{ Technology } \\
\hline $\begin{array}{l}\text { Technology improvements (generation and } \\
\text { controls) }\end{array}$ & $\checkmark$ & $\checkmark$ & $\checkmark$ & $\checkmark$ \\
\hline $\begin{array}{l}\text { Improved flexibility management (technical } \\
\text { aspects) }\end{array}$ & $\checkmark$ & $\checkmark$ & $\checkmark$ & \\
\hline Electrification of the transportation sector & & $\checkmark$ & $\checkmark$ & \\
\hline Cyber-attacks with long, widespread outages & & $\checkmark$ & & $\checkmark$ \\
\hline $\begin{array}{l}\text { Physical disruptions with long, widespread outages } \\
\text { (e. g., weather, attacks) }\end{array}$ & & $\checkmark$ & $\checkmark$ & $\checkmark$ \\
\hline \multicolumn{5}{|l|}{ Policy and Regulatory } \\
\hline $\begin{array}{l}\text { Environmental regulations (e.g., carbon market or } \\
\text { carbon tax) }\end{array}$ & $\checkmark$ & $\checkmark$ & & \\
\hline $\begin{array}{l}\text { Policies to accelerate prevention of and recovery } \\
\text { from cyber-attacks }\end{array}$ & & $\checkmark$ & $\checkmark$ & \\
\hline $\begin{array}{l}\text { Improved flexibility management (policy and } \\
\text { regulatory) }\end{array}$ & $\checkmark$ & $\checkmark$ & $\checkmark$ & \\
\hline $\begin{array}{l}\text { Evolved regulations and policies focused on value of } \\
\text { services }\end{array}$ & & $\checkmark$ & $\checkmark$ & \\
\hline Interconnection challenges & & & & $\checkmark$ \\
\hline $\begin{array}{l}\text { Improved bulk system interconnections and sub- } \\
\text { hourly markets }\end{array}$ & $\checkmark$ & & $\checkmark$ & \\
\hline \multicolumn{5}{|l|}{ Market } \\
\hline National carbon market or carbon tax (market) & $\checkmark$ & $\checkmark$ & & \\
\hline Improved flexibility management (market aspects) & $\checkmark$ & $\checkmark$ & $\checkmark$ & \\
\hline Evolved market rules focused on value of services & & $\checkmark$ & $\checkmark$ & \\
\hline $\begin{array}{l}\text { Improved bulk system interconnections and sub- } \\
\text { hourly markets }\end{array}$ & $\checkmark$ & & $\checkmark$ & \\
\hline \multicolumn{5}{|l|}{ Financing } \\
\hline $\begin{array}{l}\text { Reduce capital uncertainties for clean generation } \\
\text { (VRE, clean coal, nuclear), DG, bulk and distributed } \\
\text { storage, value of services flexibility, interactivity), } \\
\text { and cyber-attack and physical disruption prevention }\end{array}$ & $\checkmark$ & $\checkmark$ & $\checkmark$ & \\
\hline $\begin{array}{l}\text { Increased capital and financing for consumer- } \\
\text { purchased resources }\end{array}$ & & $\sqrt{ }$ & & $\checkmark$ \\
\hline $\begin{array}{l}\text { Natural gas (NG ) pipeline expansion limits and NG } \\
\text { fracking environmental restrictions }\end{array}$ & $\checkmark$ & $\checkmark$ & & \\
\hline \multicolumn{5}{|l|}{ Utility Business Models } \\
\hline $\begin{array}{l}\text { Evolved business models focused on value of } \\
\text { services }\end{array}$ & & $\checkmark$ & $\checkmark$ & \\
\hline Improved flexibility management (business aspects) & $\checkmark$ & $\checkmark$ & $\checkmark$ & \\
\hline $\begin{array}{l}\text { Involvement of non-utilities (including third-party } \\
\text { owners, customers) with different } \\
\text { interests/business cases }\end{array}$ & & $\checkmark$ & $\checkmark$ & $\checkmark$ \\
\hline
\end{tabular}




\section{Understanding Rapid DER Growth on Utility Business Functions}

This section identifies the areas where DG PV interact with overall utility business operations, in a high-level way, across all levels of the utility as a business. The authors decided to focus on the rapid growth of DER future, and distributed solar PV generation specifically, because it is expected to require the widest and deepest utility business changes than other futures envisioned. Utilities are generally structured to operate in an environment that is based on large central station generation connected to the high voltage transmission system with two-way power flows, then down to the distribution system where power flows in one direction - from the substation to the end customer. The rapid growth DER future adds the challenge of many small sized distributed generating plants interconnected to the distribution system (not transmission).

The Rapid DER future may entail DERs benefitting from new valuations, new requirements, and cost decreases. Modernization and optimization (twoway power flow, communications, IT) of the distribution grid could be financed by a mix of rate base and public sources of capital. Utility customers, DER developers, thirdparty owners, and electric utilities may begin to value and benefit from DG, energy efficiency, and new energy storage options. These distributed resources not only have the impact of reducing load at the customer level, but also of dumping excess generation onto the electric grid when customer demand is lower than the solar generation output. In deregulated markets, the operator of the "wires"

Utilities are likely to face a future in which solar technologies contribute a greater portion of electricity generation. Before reaching high penetration of $\mathrm{PV}$, penetration may reach an interim, notable level that could begin to impact utility planning and operations in a variety of ways. It is important to note that penetration does not need to reach a "high" level for the utility to need to take action. The metric high penetration appears in various permutations throughout state and FERC interconnection rules, state renewable portfolio standards, technical papers, and general discussions, but the term used in one context may not be the most appropriate for another (Coddington 2014). High penetration is a widely used, but often poorly defined term and could refer to power or energy over a particular area (e.g., circuit, feeder, utility service territory, state). Examples include capacity penetration, energy penetration, PV penetration, customer PV penetration, meter penetration, net energy metering (NEM) penetration, ampacity penetration, generation penetration, substation penetration, and rooftop penetration. An NREL white paper discussing the different definitions of high penetration and when each is most useful is forthcoming. balances generation, storage, and demand and may be supported by decoupling. In vertically integrated markets, the "Energy Services Utility" may be incentivized to increase system flexibility to lower overall costs by providing energy services and efficiency to the end customer (not energy). Utilities may also own DERs, allowing for the potential for energy efficiency and grid services to become profit centers. This future state, although experienced in a few areas in the United States and in Europe, is largely not yet experienced by most U.S. utilities and will likely require utilities to change their planning and operations in order to maintain grid reliability.

Before moving on to the impact DER has specifically on the planning and operation functions of a single utility, the authors want to quickly touch on the importance of considering the impact 
that DER can have on the larger U.S. electric system. Due to the interconnected nature of the U.S. electric grid, the impacts of a rapid DER growth future will likely extend beyond that single utility and may propagate through the electric system. And if two neighboring utilities, or many utilities in a region, are dealing with rapid DER growth, the impacts may overlap in likely new and potentially, surprising ways. This suggests that larger coordination at the state or regional level could be beneficial.

As shown in Figure 1, the amount of customization needed in the U.S. electric sector in response to a rapid DER growth future is likely to be directly related to how central or decentralized the solutions are. To enable substantial DER, policymakers may want to consider more decentralized policy actions that may require customization for success. Fragmented energy services that are not coordinated more broadly across community, state, or regional levels will be decentralized in nature and require substantial resources to integrate these services, and their value, into the existing system. And because they are not coordinated more broadly, they may only lead to an incremental evolution of the electric system. Community-scale energy services (which could include a state or regional level) are emerging and, if coordinated, could lead to revolutionary change. If designed properly, they likely will not require the same level of customization that fragmented energy services could. The benefits of coordination could decrease customization and make it easier for utilities and the DER providers to seamlessly integrate their programs across states and within regions, thus decreasing the overall cost of implementation. In other words, planned coordination could lead to a more efficient response to a rapid DER growth future. This would be a suitable topic for further exploration in a follow-on analysis and report.

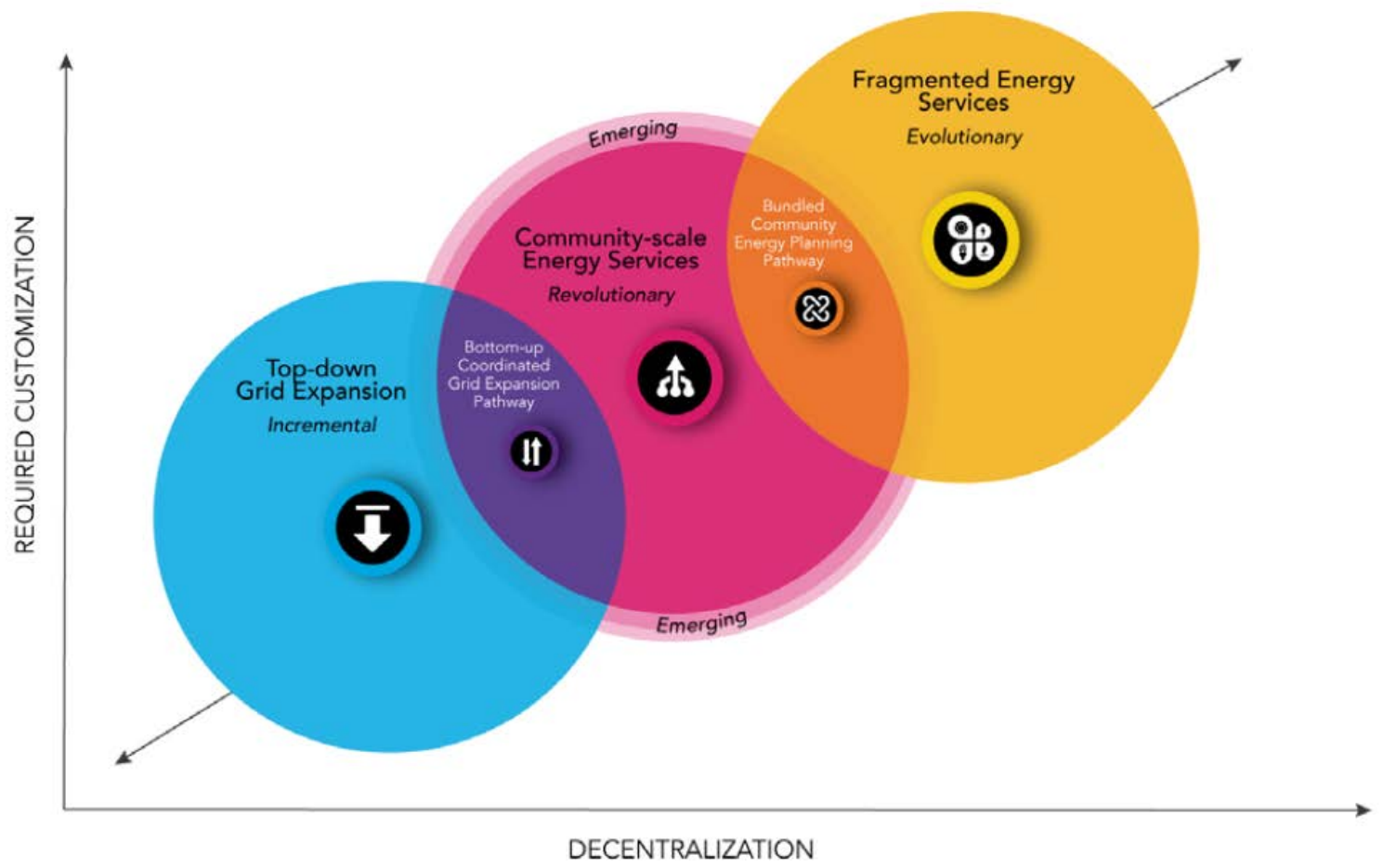

Figure 1. The continuum of pathways to support increased decentralization requires increased customization

Source: Zinaman et. al. 2015 


\section{Functions of the Regulated Utility}

Next, the case of an individual utility is considered. Vertically integrated utilities, and in particular IOUs, have responsibility for the full gamut of services and investments required to provide electric service to their customer base. Their decisions, plans, and operations are reviewed and approved by their regulators. In reality, the typical utility has a wide variety of functions required for successful system operation. Figure 2 provides a sample breakdown of the business units in a typical utility and the types of activities that each of those groups perform.

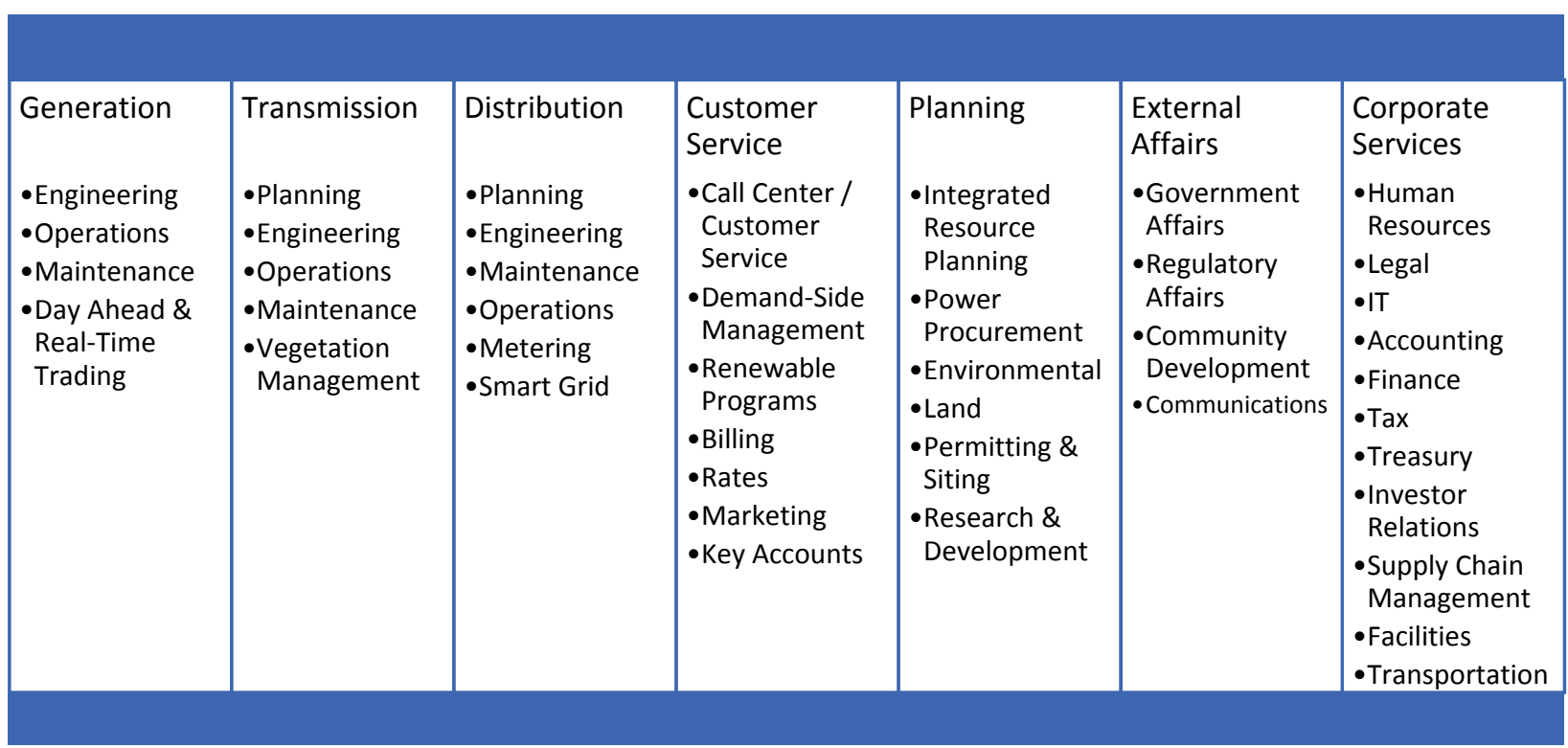

Figure 2. Typical utility business units

Figure 3 provides a frame of reference for how roles and responsibilities can be organized. In addition to the standard generation, transmission, and distribution functions, utilities place a strong emphasis on customer service. This can include everything from regional offices to a centralized call center for customers to interact directly with the utility, all the way up to specific energy efficiency and other demand-side management program offerings designed to assist customers with better managing their energy consumption.

Under today's paradigm, where central station generation and one-way power flows dominate the landscape, processes and procedures exist that either facilitate or - in some instances prevent certain employees from collaborating. For example, the Integrated Resource Planning process necessarily relies on the collection of information from a wide variety of groups across all business units. Conversely, FERC's Standards of Conduct specifically prohibit the employees responsible for transmission planning and operations from sharing information that could be considered as providing a competitive advantage or selective treatment with employees responsible for generation dispatch. These conflicts should be addressed to ensure a successful transformation of the electric sector today.

IOUs, in all instances, are regulated entities that must interact with regulators. These external interfaces occur not only for those obvious regulatory climates, but even down to the community level for economic development and related processes. 
And similar to any other large business, utilities internalize a range of departments that support all other parts of the organization. These "corporate services" help facilitate the ongoing utility operations.

\section{Solar and Utility Impact Areas}

As the utility industry adapts to a world with increased and rapid growth of DER, the ways in which the utility reacts can vary widely. Distributed solar PV may be the most impactful new resource that will directly affect utility planning and operations over the long term. ${ }^{3}$ For the first time in the electric industry's history, mass adoption of customer-sited generation is plausible; indeed, it is already occurring and impacting utility operations in places like Hawaii. Distributed solar has the potential to touch virtually all departments within a utility, and can drive significant organizational changes - even at small levels of penetration (Edge and Taylor 2014).

Determining the myriad of ways that distributed solar can impact a utility requires an understanding of how these resources are treated today. The solar impact areas represented in Figure 3 are an attempt to identify high-level, cross-cutting implications distributed solar PV could impose across a utility's operations. Each of these solar impact areas has the potential to influence how the utility performs across a variety of functions, roles, and responsibilities.

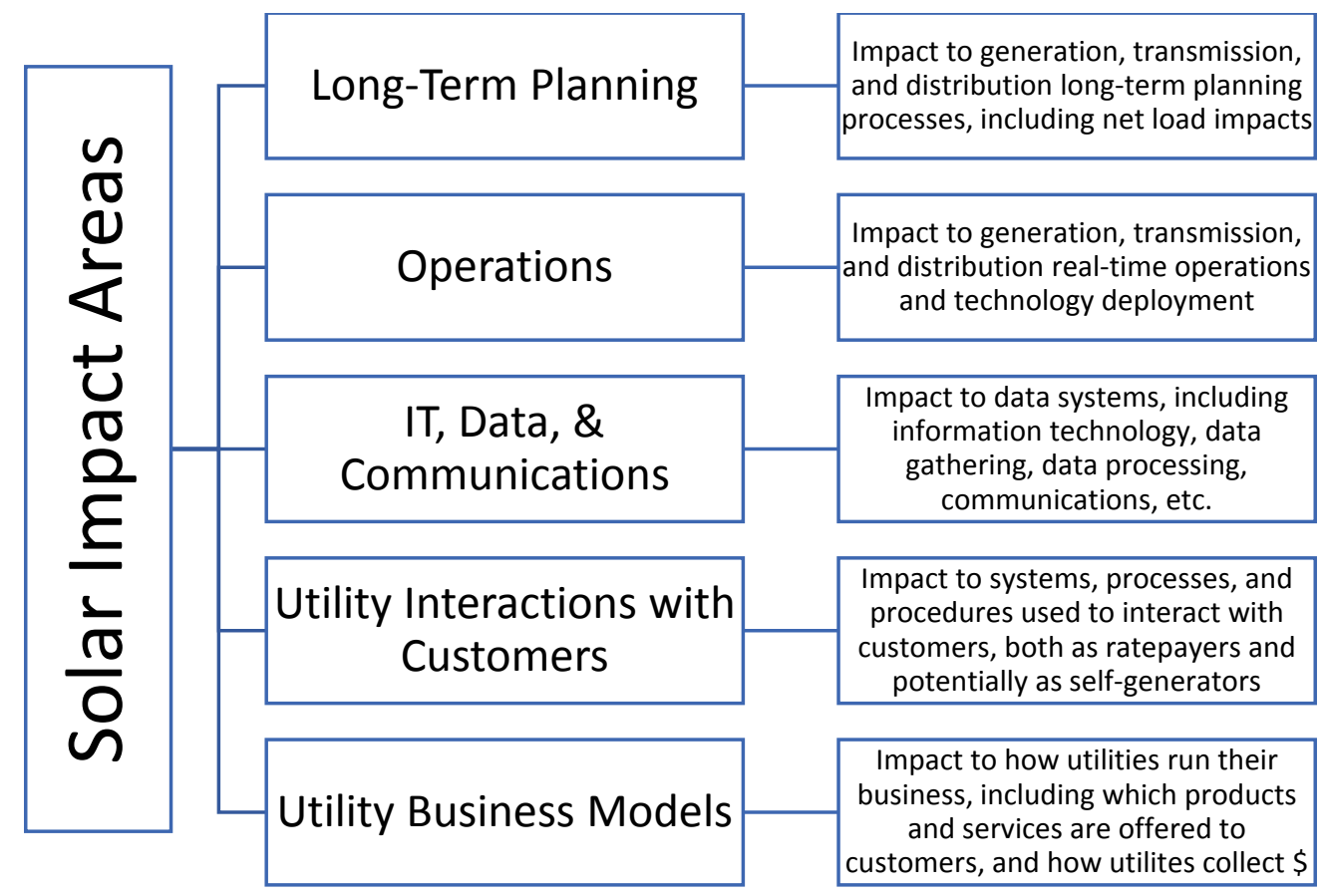

Figure 3. Solar impact areas

To illustrate the highest potential areas of distributed solar impact on utility functions, roles, and responsibilities, the authors identified 15 distinct Utility Impact Areas that are most likely to be influenced by increasing DGPV penetrations. ${ }^{4}$ The Utility Impact Areas are described in Table 2.

\footnotetext{
${ }^{3}$ Commercially available storage at the distribution level will likely be impactful once it becomes economic.

${ }^{4}$ While some of Utility Impact Areas directly correlate with the business units (Figure 1), others describe specific activities, functions, and technologies that are either embedded within or shared across those business units.
} 
Table 2. Utility Impact Areas

\begin{tabular}{|c|c|}
\hline Utility Impact Areas & Description \\
\hline $\begin{array}{l}\text { Customer Communications \& } \\
\text { Marketing }\end{array}$ & $\begin{array}{l}\text { How a utility informs its customer base of new programs, rate } \\
\text { actions, and other activities }\end{array}$ \\
\hline Call Center Operations & $\begin{array}{l}\text { Processes, technologies, and personnel required to run the } \\
\text { utility's customer call center }\end{array}$ \\
\hline Retail Rate Design & $\begin{array}{l}\text { Types of rates offered to customers, frequency and method of } \\
\text { rate cases and/or adjustments, etc. }\end{array}$ \\
\hline Regulatory Interfaces & $\begin{array}{l}\text { Filings and other interactions with federal and state } \\
\text { commissions that regulate rates and other utility activities }\end{array}$ \\
\hline Customer Information Systems & $\begin{array}{l}\text { Information Technology (IT) systems dedicated to managing } \\
\text { customer information; includes Customer Information System } \\
\text { (CIS), Meter Data Management System (MDMS), etc. }\end{array}$ \\
\hline $\begin{array}{l}\text { Utility Data Tracking \& } \\
\text { Utilization }\end{array}$ & $\begin{array}{l}\text { The methods, usage, analytics, and warehousing of all customer } \\
\text { and system data, collected on a routine and non-routine basis }\end{array}$ \\
\hline Real-Time Communications & $\begin{array}{l}\text { Forms of technology leveraged for communicating with end } \\
\text { points on the system and the round-trip latency and frequency } \\
\text { of the communications between the central utility decision- } \\
\text { making applications / personnel and those end points }\end{array}$ \\
\hline Integrated Resource P & $\begin{array}{l}\text { Process for creating a long-term plan (typically } 15+\text { years) that } \\
\text { balances supply- and demand-side resources against future } \\
\text { customer load requirements }\end{array}$ \\
\hline Transmission Planning & $\begin{array}{l}\text { Process for developing a long-term plan (typically } 10+\text { years) for } \\
\text { transmission additions and upgrades that supports all the } \\
\text { transmission of electricity across the balancing authority area }\end{array}$ \\
\hline Distribution Planning & $\begin{array}{l}\text { Process for developing a near-term plan (typically 5-7 years) of } \\
\text { capital expenditures for the distribution system, including asset } \\
\text { replacement and new build / growth areas }\end{array}$ \\
\hline Personnel Needs / Adjustments & $\begin{array}{l}\text { Staffing requirements and organizational accountabilities of } \\
\text { different business units and roles within the utility }\end{array}$ \\
\hline Distribution System Operations & $\begin{array}{l}\text { Physical operations and maintenance of the distribution system, } \\
\text { including how different deployed assets react to system issues }\end{array}$ \\
\hline $\begin{array}{l}\text { Transmission System } \\
\text { Operations }\end{array}$ & $\begin{array}{l}\text { Physical operations and maintenance of the transmission } \\
\text { system }\end{array}$ \\
\hline $\begin{array}{l}\text { Generation Dispatch } \\
\text { Procedures }\end{array}$ & $\begin{array}{l}\text { Real-time and day ahead economic and out-of-merit dispatch } \\
\text { decisions of the generation fleet, including ancillary services and } \\
\text { reserve requirements needed to ensure reliability }\end{array}$ \\
\hline Technology Deployment & $\begin{array}{l}\text { Related to planning and operations, the decision-making } \\
\text { process on the types of utility assets and technologies to deploy } \\
\text { on the electric system to ensure reliability }\end{array}$ \\
\hline
\end{tabular}

A key element to understanding solar's impact on utility business operations is to compare the solar impact areas and each Utility Impact Area. The goal here is to understand the touchpoints where solar interacts with and can influence future utility operations. To better understand that interplay, the authors leveraged a session at SEPA's Utility Solar Conference, held in San Diego, California, in April 2015. For discussion purposes, session participants were asked to imagine a 
future where rapid adoption of DERs occurred on their system, to break into smaller groups, and to discuss and debate how impactful high penetrations of distributed solar PV would be across various aspects of their organizations. These small group discussions helped validate the breakdown of Solar and Utility Impact Areas and identified where relationships exist. The results of these discussions are highlighted in Figure 4 thru Figure 8. While not every solar impact area will influence each Utility Impact Area, it became clear during the conference session that the different ways distributed solar manifests itself is both broad and deep across the functional roles of the typical vertically integrated IOU.

The next five sections consider the solar impact areas individually in each section below, comparing them against the 15 Utility Impact Areas. Any Utility Impact Area that is not impacted by DGPV was made light blue to deemphasize the relationship. Those kept in dark blue have a clear relationship to the solar impact area, as described in the text.

\section{Long-Term Planning}

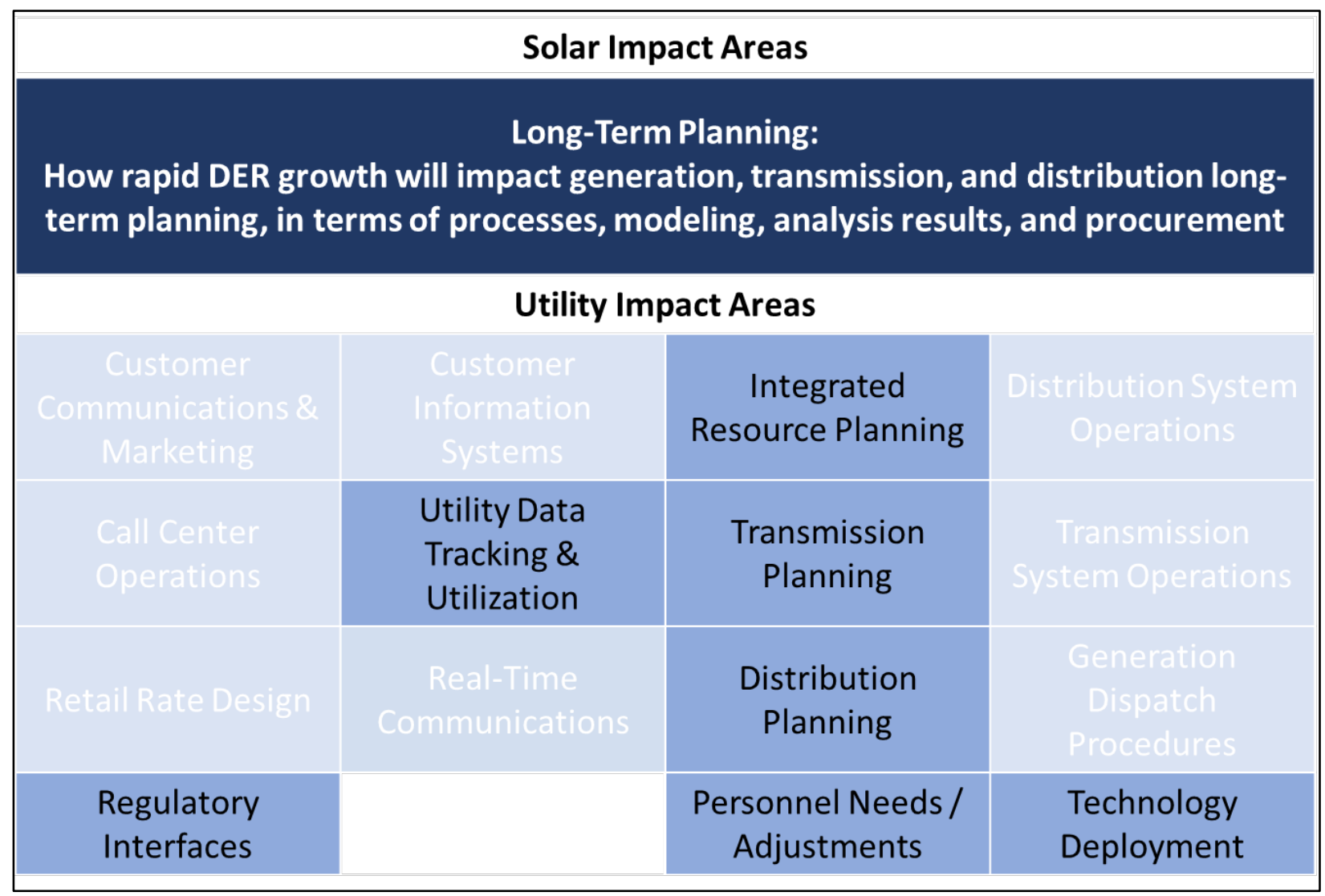

Figure 4. Impact of solar on long-term planning activities

High levels of penetration of distributed solar impacts utility long-term plans across many business functions. Added generation at the edge of the grid can either be treated as a net load reduction or as a resource in the integrated resource planning (IRP) process, and as penetration rises, distribution plans likely would have to be adjusted to account for feeder-specific impacts and distribution technology deployment. Both of those factors may cause long-term transmission addition plans to change. In addition, because many utilities file IRPs with their state 
commissions, they will probably have to change how they begin to communicate resource planning decisions to their regulators. A key component of determining the impacts to long-term plans will be integrating a significant amount of granular data on system loads and asset health as solar penetration increases.

\section{Utility Operations}

\begin{tabular}{|c|c|c|}
\hline \multicolumn{3}{|c|}{ Solar Impact Areas } \\
Operations: \\
How rapid DER growth will impact your generation, transmission, and distribution \\
real-time operations and technology deployment
\end{tabular}

Figure 5. Impact of solar on utility operations

The addition of variable generation resources will likely directly impact utility real-time operations. To manage these resources in real-time, utilities may have to alter their generation dispatch curves, particularly to be prepared to manage swings in load resulting from the variability in solar output.

On the customer interface front, utilities will likely want to be more knowledgeable about which customers have generation onsite, which may require modifications to Customer Information Systems (CIS). The call center for the utility - often the first touch point when issues occur for a customer - may require updated training for customer care representatives to better familiarize them with the types of questions that would arise from this class of customers. 


\begin{tabular}{|c|c|c|}
\hline & Solar Impact Areas \\
\hline IT, Data, Communications: & \\
How rapid DER growth will impact your data systems, including \\
information technology, data gathering, data processing, communications, cyber \\
security, etc.
\end{tabular}

Figure 6. Impact of solar on IT, data, and communications infrastructures

As distributed solar penetration increases, the needs and requirements imposed upon the IT department are expected to increase exponentially. Thousands of new endpoints will exist; each could have the potential to collect, store, and integrate sub-minute information on system performance that could be used for distribution system health analytics. Capturing this amount of data requires a robust and secure communications infrastructure, and taking action on that data requires a powerful analytics platform that can monitor the health of the system and - potentially - make real-time decisions on how deployed technologies react (such as smart inverters, load tap changers, cap banks, etc.). These data can also be extremely useful to the call center, where information on outages and estimated restore times can benefit customer care representatives fielding calls. At a higher level, pushing this wealth of information upstream into the long-term planning processes can result in higher quality considerations on the timing and level of resource needs. 


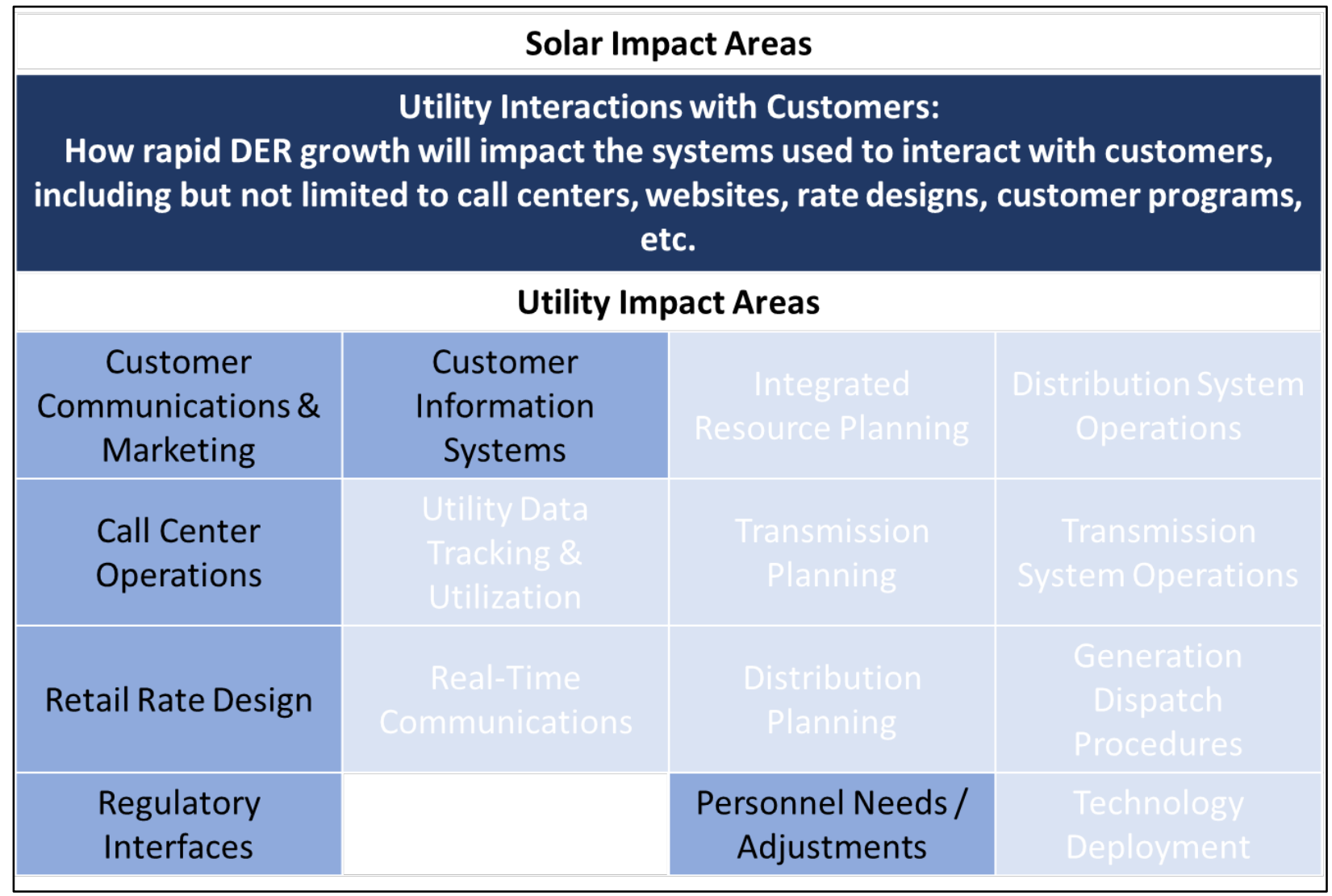

Figure 7. Impact of solar on utility interactions with customers

The ways in which a utility interacts with its customers has changed significantly over the past decade and will likely continue to evolve in the decades to come. The primary driver of this change is around how technology advancements have enhanced each customer's ability to both understand and engage in their energy consumption. Many utilities currently offer customer energy portals to view historical consumption information. As DERs proliferate, ideally designed portals would provide meaningful and actionable information to the end consumer so that the technology's full capabilities can be leveraged. Indeed, many third-party technology vendors already offer smart phone "apps" that provide instantaneous information about demand within the home, although they have not been deployed widely. In addition, these types of portals can greatly increase a given customer's education level on how actions impact usage (and therefore, bills).

In order to facilitate all of these new customer-enabling technologies and programs, utilities may be faced with reimagining the makeup of their workforce. Realignments in how business units are organized, the skill sets and job levels needed to plan for and operate the grid of the future, and other changes could be in store. 


\begin{tabular}{|c|c|c|c|}
\hline \multicolumn{4}{|c|}{ Solar Impact Areas } \\
\hline \multicolumn{4}{|c|}{$\begin{array}{l}\text { Utility Business Models: } \\
\text { How rapid growth of DER will impact the way you run your business, } \\
\text { including which products and services you offer to your customers }\end{array}$} \\
\hline \multicolumn{4}{|c|}{ Utility Impact Areas } \\
\hline $\begin{array}{l}\text { Customer } \\
\text { Communications \& } \\
\text { Marketing }\end{array}$ & $\begin{array}{l}\text { Customer } \\
\text { Information } \\
\text { Systems }\end{array}$ & $\begin{array}{l}\text { Integrated } \\
\text { Resource Planning }\end{array}$ & $\begin{array}{c}\text { Distribution System } \\
\text { Operations }\end{array}$ \\
\hline $\begin{array}{l}\text { Call Center } \\
\text { Operations }\end{array}$ & $\begin{array}{l}\text { Utility Data } \\
\text { Tracking \& } \\
\text { Utilization }\end{array}$ & $\begin{array}{l}\text { Transmission } \\
\text { Planning }\end{array}$ & $\begin{array}{c}\text { Transmission } \\
\text { System Operations }\end{array}$ \\
\hline Retail Rate Design & $\begin{array}{c}\text { Real-Time } \\
\text { Communications }\end{array}$ & $\begin{array}{l}\text { Distribution } \\
\text { Planning }\end{array}$ & $\begin{array}{l}\text { Generation } \\
\text { Dispatch } \\
\text { Procedures }\end{array}$ \\
\hline $\begin{array}{l}\text { Regulatory } \\
\text { Interfaces }\end{array}$ & & $\begin{array}{l}\text { Personnel Needs / } \\
\text { Adjustments }\end{array}$ & $\begin{array}{l}\text { Technology } \\
\text { Deployment }\end{array}$ \\
\hline
\end{tabular}

Figure 8. Impact of solar on utility business practices

One of the key changes that can be observed today is that electricity is less and less a commodity; rather, the utility is starting to sell energy as a service (Propper 2015; NYS DPS 2014; Cory and Aznar 2014; Aggarwal and Burgess 2014; Newcomb et al. 2013; Harvey and Aggarwal 2013; GE Digital Energy 2013; Richter 2012). This shift in thinking and operations also means that the method with which utilities discuss their business model with regulators is likely to change as well. At high levels of solar penetration, utilities may need to look at the products and services they offer to customers and determine - with their regulators - what the right roles are for the utility going forward. The conversation could include how the utility is paid for the services it provides as well. This type of strategic planning exercise cuts across all types of utility functions and requires a holistic review of how the utility-customer relationship could evolve.

\section{Holistic Strategy Development}

The authors facilitated discussion during an industry meeting of (predominantly) utility employees to understand how they viewed the relative impact of high penetrations of DERs on their operations. Participants were asked to rate the level of impact on each of the categories on a scale of 1 to 5, with 5 being the most impactful. Results are shown in Figure 9. Precisely because of the fact that distributed solar cuts across so many utility functions and responsibilities, the 
participants saw nearly universal major impacts during the session. ${ }^{5}$ Transmission planning is anticipated to be the least impacted - and even that was identified as having more change than not, on average. The areas listed below relevant to utility planning and operations are explored in more detail in the next section.

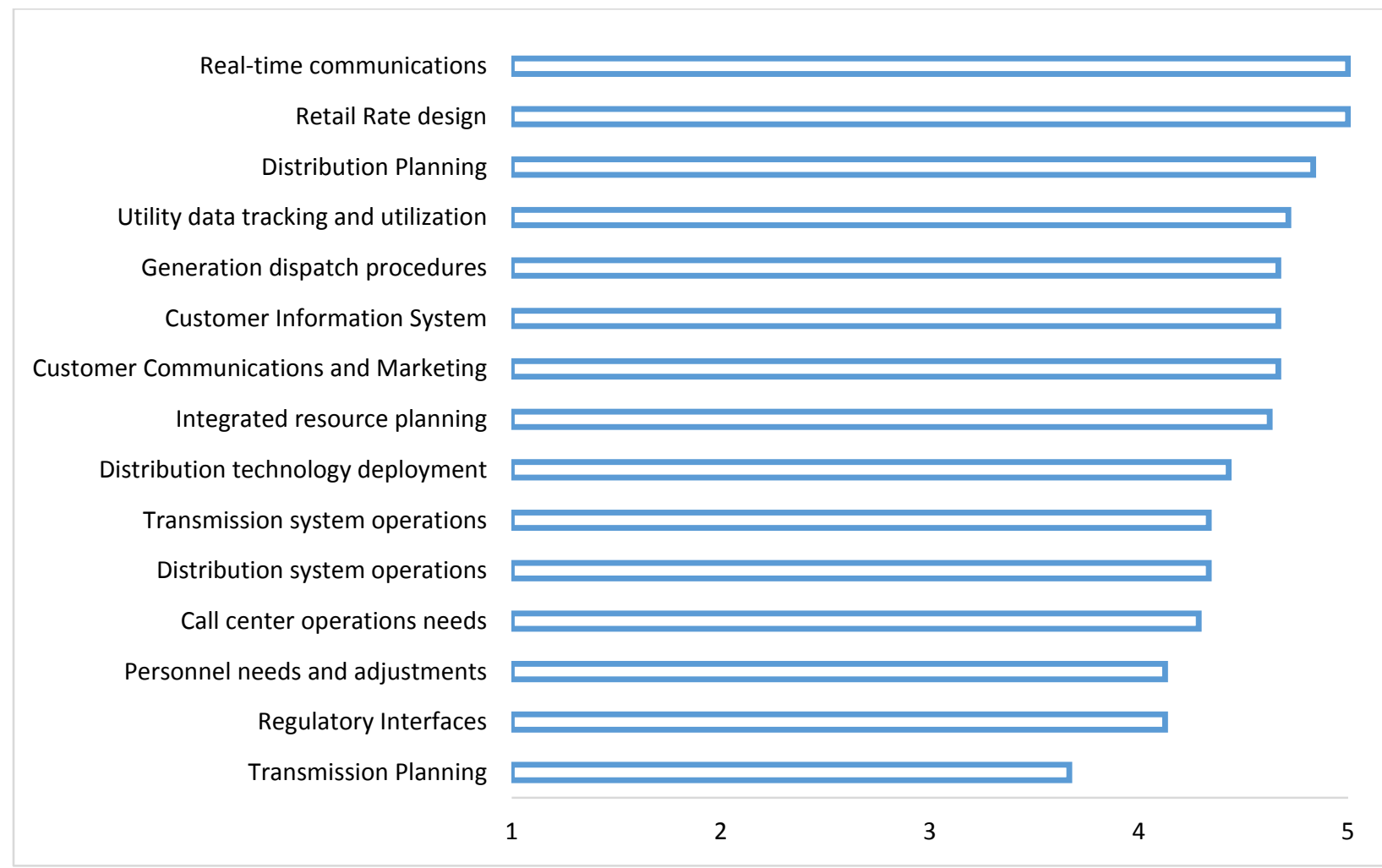

Figure 9. Average Level of impact of rapid DER growth on Utility Impact Areas

Simply put, the utility industry is at a crossroads. The changing landscape of technology options for end-use consumers is likely to enable fundamentally higher levels of expectations for utilities. The fact that a rapid DER growth future is seen as likely by many in the industry merely underscores the need for each utility to begin the process of integrating new technologies, processes, skill sets, etc. into typical business functions sooner rather than later. To help underscore this need, the next section will take a deeper dive on planning and operations at utilities to identify requirements for safe, reliable, and cost-effective services in a rapid DER growth future.

\footnotetext{
${ }^{5}$ Figure 9 represents the views of 11 different breakout groups made up of more than 50 utility representatives in total.
} 


\section{Planning and Operations - Realizing Tomorrow's Requirements Today}

To build on the overview of DER impacts on utilities across all their business functions, this section describes and deeply examines potential changes to utility planning and utility operations that can support DER and PV adoption. It focuses on how DER and DG PV could directly result in modifications to existing generation, transmission, and distribution planning and operations procedures, systems, protocols, and resources that will probably be required in a future where DER adoption has achieved critical mass. To supplement the discussion and provide context on existing activities, the authors conducted an online quantitative survey of IOUs, to which ten utilities responded. Those results are included within the following sections.

\section{Long-Term Planning Activities}

Rapid growth of DER is expected to precipitate changes to utility planning. The three areas needing attention in the planning process are IRP, transmission planning, and distribution planning. While IRPs are often filed publicly on a routine schedule, often in alternating years, all forms of planning occur at least annually at a majority of utilities surveyed. IRPs typically cover 15-year time horizons (though can range from 10-20+ years), while transmission plans tend to cover only 10 years. According to survey results, distribution plans are either focused on 5- or 10 -year horizons.

Some utilities do resource planning in parallel with transmission planning since adding large centralized generating stations also requires transmission system changes, but over half of survey respondents indicated that the transmission planning process actually occurs separately and the results are treated as IRP inputs. At this time, most utilities questioned do distribution planning as a separate process from resource and transmission planning, with only one-third of respondents indicating that distribution and transmission plans are optimized together. Because DERs will mostly connect to the distribution system and could create two-way power flows, it will be essential to increase the connectivity between the three planning processes to maintain system reliability.

\section{Distribution Planning}

Because DER interconnects at the distribution level, planning at the distribution level will become more complex and the utility role will be critical for maintaining system reliability. DERs are close to the load and therefore, they significantly reduce losses that occur due to the transmission of electrons across long distances. It also has the additional benefit of potentially deferring system upgrades at the distribution level. However, because of the potential for twoway power flows across design protections originally built for one direction fault current and back feeding from the upstream feeder, it would be possible to cause faults that existing protection systems in the distribution system cannot sense. Additional relaying and other design schemes could counteract the effect of DER reducing the effectiveness of existing equipment.

In addition to electrical equipment additions, communications capabilities will allow for dynamic adjustment to the variability of DER. These two-way communications will be essential for maintaining grid stability at the distribution level. A major complicating factor is that the utility can have hundreds to thousands of distribution circuits that normally were designed to handle 
local conditions. Given such a diverse set of starting conditions, DER penetration could have a different effect on each distribution circuit, resulting in different design applications to combat DER's inherent characteristics. Over half of utility survey respondents indicated that, today, they do not have the capability to monitor assets on the distribution system in real-time that would inform them of grid disturbances caused by DERs. More interestingly, the same number of utilities are experiencing isolated issues on the distribution system caused by DER penetration that they manage today with existing resources. As penetration increases over time, these isolated incidents may become more frequent and incremental technology solutions may be required to address them. Sub-second measurement through synchrophasors or phase modulation units can be leveraged to provide real-time insights; cross-referencing that information with other data sources so that analytics can be performed on sub-second levels can provide both strategic insights and, potentially, real-time solutions to grid disturbances.

An engineering review for electrical equipment modifications and the expected communications infrastructure needed is considered essential by our interviewees, who recommend incorporating the reviews into distribution planning considerations. This equipment review could allow new technologies, features, and characteristics to be real options and thus be adopted as company standards for asset upgrades and replacements on the distribution system. This will entail identifying the highest priority equipment gaps that could keep the grid stable and reliable when addressed, and could provide signals to industry of the technology need. Further, utility ownership of the smart inverter, along with the ability to have two-way communications, can provide a long-term avenue for the utility to maintain grid stability and reliability.

At the distribution level, having real-time data through the smart meter and smart inverter enables distribution operations to react to and plan for system disturbances that may occur due to DER variability (Davidovich and Sterling 2014). This approach of changing the way assets are defined would necessarily require proactive engagement with regulators to weigh the benefits and costs so that the best approach for all customers can be incorporated into utility plans.

\section{Integrated Resource Planning}

Regardless of whether or not they are interconnected behind or in front of the utility meter, DERs provide energy and potentially, capacity benefits to the utility and its customer base. At significant levels of penetration, this means generation and distribution additions that otherwise would get planned for, and ultimately built, could be deferred.

Complicating the IRP review process is the fact that the majority of utilities tend to treat distributed generation as a net load impact (Sterling et al. 2013). While netting DG behind the customer meter is adequate at low penetration levels, it hides the variability of solar inside of the utilities' load forecast, not only on an energy basis, but also on a capacity basis. Neither the actual customer load nor the solar generation is clear, which makes it harder to predict and plan; this is exacerbated as penetration increases. The potential future with rapid growth DER is expected to change the way utilities do resource planning from treating DER as a net load impact to an actual generation resource. Doing resource planning this way will allow for the utility to do "what if" analyses around both their customer load and the variability of solar production. Together, these are expected to provide more granular information, which could better inform a more robust generation resource plan. 
Related to the inherent variability in production from these resources due to weather fluctuations, the future utility may need to invest in the ability to conduct long-term planning analyses on a time interval significantly shorter than currently practiced, or even envisioned. Current production cost modeling is done on an hourly basis for the duration of the planning horizon. Trying to run these on a shorter time basis, such as five minutes, is not practical due to the heavy burden it places on computing power (Sterling et al. 2013). Regardless, at high levels of penetration the ability to understand the potential fluctuations in these resources on a level more granular than an hour is critical to ensuring that the appropriate conventional resources are added to the system to maintain grid reliability. Alternatively, battery energy storage systems (BESS) or other storage devices could provide a viable alternative to managing intra-minute variability, ensuring a smoother production curve for the remaining assets on the system to dispatch against. Demand response is another option. There are many other ways to add flexibility to the electric system that span system operation, market mechanisms, load response, flexible generation, networks, and storage (Cochran et al. 2014b). Figure 10 shows a snapshot in time of the relative economics of integration options across these ways of adding flexibility. The options costs are system dependent and constantly evolving.

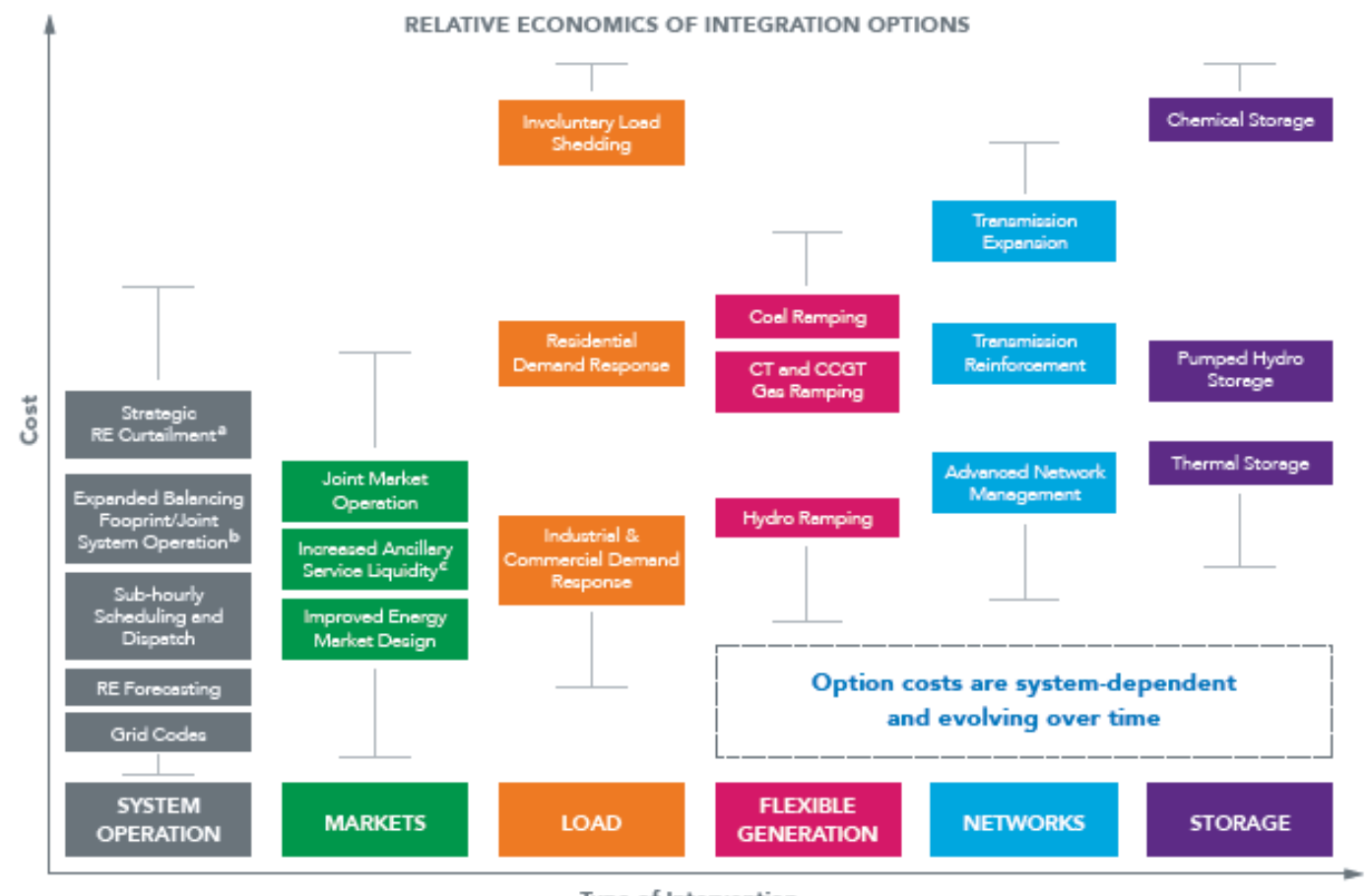

Type of Intervention

Note: Example integration options. Relative costs are illustrative, as actual costs are system dependent.

a There is a tradeoff between costs of flexibility and benefits of reduced (or no) curtailment, hence a certain level of curtailment may be a sign that the system has an economically optimal amount of flexibility.

b Joint system operation typically involves a level of reserve sharing and dispatch co-optimization but stops short of joint market operation or a formal system merger.

c Wind power can increase the liquidity of ancillary services and provide generation-side flexibility. Curtailed energy is also used to provide frequency response in many systems, for example Xcel Energy, EirGrid, Energinet.dk.

Figure 10. Mechanisms for increasing flexibility

Source: Cochran et. al 2014b 
Finally, the interplay between DER penetration and customer load will be critical to understand, as evidenced by California's "duck curve" and the resulting ramping requirements imposed late in the day. Understanding the magnitude of these ramps and the resources available to manage them will likely play a large role in future utility IRP processes (Joe et al. 2015).

\section{Transmission Planning}

Planning at the transmission and distribution level has, thus far, been done as separate processes. The traditional consideration of planning around large, centralized stations - with electrons flowing from generators through the transmission and distribution systems and ending at the enduse customer - changes in the rapid DER future state. DER operation impacts precipitate a need to capture potentially cascading and interrelated impacts as opposed to the traditional serial planning done with the large centralized station model.

In the rapid DER future case, at higher penetrations, the distribution system is expected to interact more with the transmission system; the distribution system can contribute to and influence system dynamics - positively through providing aggregated services, or negatively by contributing to disturbances. Because of the potential to export to the electric grid, or in the very least appear to serve load locally, this is expected to displace central station generation. These centralized generating facilities are assets that currently provide both frequency and voltage support to the transmission system in addition to power supply functions. Any loss of these vital support functions necessitates their replacement through other means considered during planning. Whether it is through additional electrical equipment, DER smart inverter functions, or other means, the transmission planner will need to have accurate and dependable data for planning to maintain grid reliability and stability. Additional specialized electrical equipment can contribute to voltage and frequency stability and enhanced communications capabilities, and when properly planned, can be built into the system to allow for the dynamic control necessary for a variable resource such as solar. From a transmission capacity standpoint, existing facilities appear to be adequate because the impact from rapid DER growth is expected to reduce power flow from centralized stations to the end customers. ${ }^{6}$

\section{Utility Operations}

Although DERs present planning hurdles, their increased presence may be more challenging from an operations perspective. Inherently, DERs (without storage) are not dispatchable and can have steep ramping levels both up and down, not only on an hourly basis, but also on a much shorter time frame. Season to season fluctuations can present challenges as well. These characteristics present operational problems that need to be managed in real-time to maintain a stable and reliable grid.

Just as load is forecast on a short-term basis, allowing for generation commitment and system operations management, forecasting DER output could be incorporated into utility operational practices to increase fidelity. Forecasting on a day-ahead basis would be helpful to the operations staffs. Intra-day forecasting will help plan for generation dispatch and distribution system operational events. California's "duck curve" shows the need for quick adaptability; the steepness of the ramping requirements coupled with short-term variability due to weather-related

\footnotetext{
${ }^{6}$ However, the addition of large, central-scale variable generation, such as wind or solar (not covered in this study), could require transmission upgrades and expansion.
} 
events highlights the importance of accurate forecast integration at hourly (or potentially smaller) intervals.

Two-way communications that transmit data are needed to sense and react to this variability. The ability to send signals to electrical equipment or smart inverters, and their ability to act in aggregate, will likely help keep the grid stable at high DER penetrations. Any automation that can be incorporated into the generation, transmission, and distribution systems is just as important as having two-way communication capabilities. Automatic voltage and frequency control equipment located at key points across the distribution grid can minimize many disturbances before they turn into grid events. Ideally, design modifications determined in the planning phase can alleviate some day-to-day operational concerns realized from the addition of high penetration of DERs.

Day-to-day design modifications and operations will likely increase the need for personnel required to handle the rapid DER scenario. At the very least, extra protection equipment, electrical relaying, switching, communications equipment, software, and other technology additions are needed, along with increased staff to design, forecast, operate, and administrate rapid DER adoption.

In 2014, SEPA partnered with ScottMadden Inc. on a multi-client benchmarking study to identify staffing levels across a group of utilities related to renewable energy functions, roles, and responsibilities. A clear correlation became evident, where utilities with more distributed solar interconnections had measurably higher numbers of Full-Time Equivalent (FTE) employees to manage those resources (Edge and Taylor 2014). While headcount may not track linearly with the number of DERs interconnected to the distribution system, clearly the increased number of customer interconnections can influence how work is performed.

In order to facilitate the understanding of what is occurring at all of the endpoints across the grid, more information and a way to process that information will be critical. Many utilities are currently turning towards advanced metering infrastructure (AMI) as a solution. With AMI deployment, the need to be able to handle large amounts of data and the proficiency for using it to the utilities' advantage arises. This requires upgrades to the MDMS and CIS, and the integration of these systems and their data with other utility software platforms such as distribution supervisory control and data acquisition (also called D-SCADA) and other data management systems. Without this level of integration, utility operators will probably have imperfect information on the health and status of the distribution system, which can have consequences upstream on the transmission system and generation dispatch sequencing due to variability in distributed resource production.

A critical component of integrating these software platforms is enabling real-time communications infrastructure with the requisite backhaul capabilities so that all the endpoint information across the system can be aggregated, summarized, analyzed, and acted upon in a very short time span. Importantly, utilities (perhaps in consultation with other key stakeholders) will determine if this aggregation and determination process is best performed in a fully centralized manner - at the head end - or if it could be delegated downstream so that feeders act independently in the best interest of their locational frequency and voltage requirements. Central questions to address include but are not limited to: whether or not the AMI system can be 
leveraged; what available frequencies (e.g., 900MHz) can be purchased to traffic utility data; the potential for home Wi-Fi services to carry critical data; and the impact of NERC cybersecurity standards and the likelihood of the utility infrastructure becoming compromised.

The influx of data from both the load side and the generation production side in the form of DER can greatly assist grid operators, who can then share with planning organizations to form the starting point for the next planning cycle. These data could feed the resource planning inputs, making their input assumptions nearer to what the system actually sees. This in turn would help transmission and distribution planners understand how the system is performing in a distributed environment. The planning cycle then feeds back into operations, allowing the utility be in a position to react to any anticipated occurrences and also modify procedures based on past experiences. Sharing information and experience between these groups as new and more granular data are gathered can greatly enhance overall lessons learned for both sides of the organization.

Lastly, communication across business units will play a central role in how well utilities adapt to the changing landscape of providing electric service to end customers. The creation of channels of communication and collaboration between billing, customer service, engineering and field operations, generation dispatch, distribution operations, and others will be most helpful for adhering to FERC's Standards of Conduct policy.

To summarize, this section considered how utility planning and operations will likely need to change once DER, and distributed solar in particular, reach higher penetration levels. Figure 11 shows the areas of planning and operations that were identified as important for integration for a utility to be flexible and prepared for rapid growth of DER.

Based on experience to date, it appears that changes will probably not only impact long-term generation, transmission, and distribution planning, but also load forecasts and thus demand planning, as well as systems, protocols, and other resources (including the need for flexibility). The need for two-way communication appears to be important for additional interactions with the customer's DG and for maintaining system reliability. Distribution planning is expected to have the most immediate needs for maintaining grid reliability. Transmission planning is envisioned to evolve over time to also incorporate distribution. Increased system flexibility and improved, two-way communications can help the utility maintain reliable operations on a day-today basis. And more personnel are likely needed to support design, forecasting, operation, administration of new protection equipment, and other protective mechanisms. A large amount of data will need to be gathered and processed, and then action will need to be taken quickly sometimes across business units. These connections appear to be critical for a utility to evolve into the flexible utility that is ready to address increased solar penetration. 


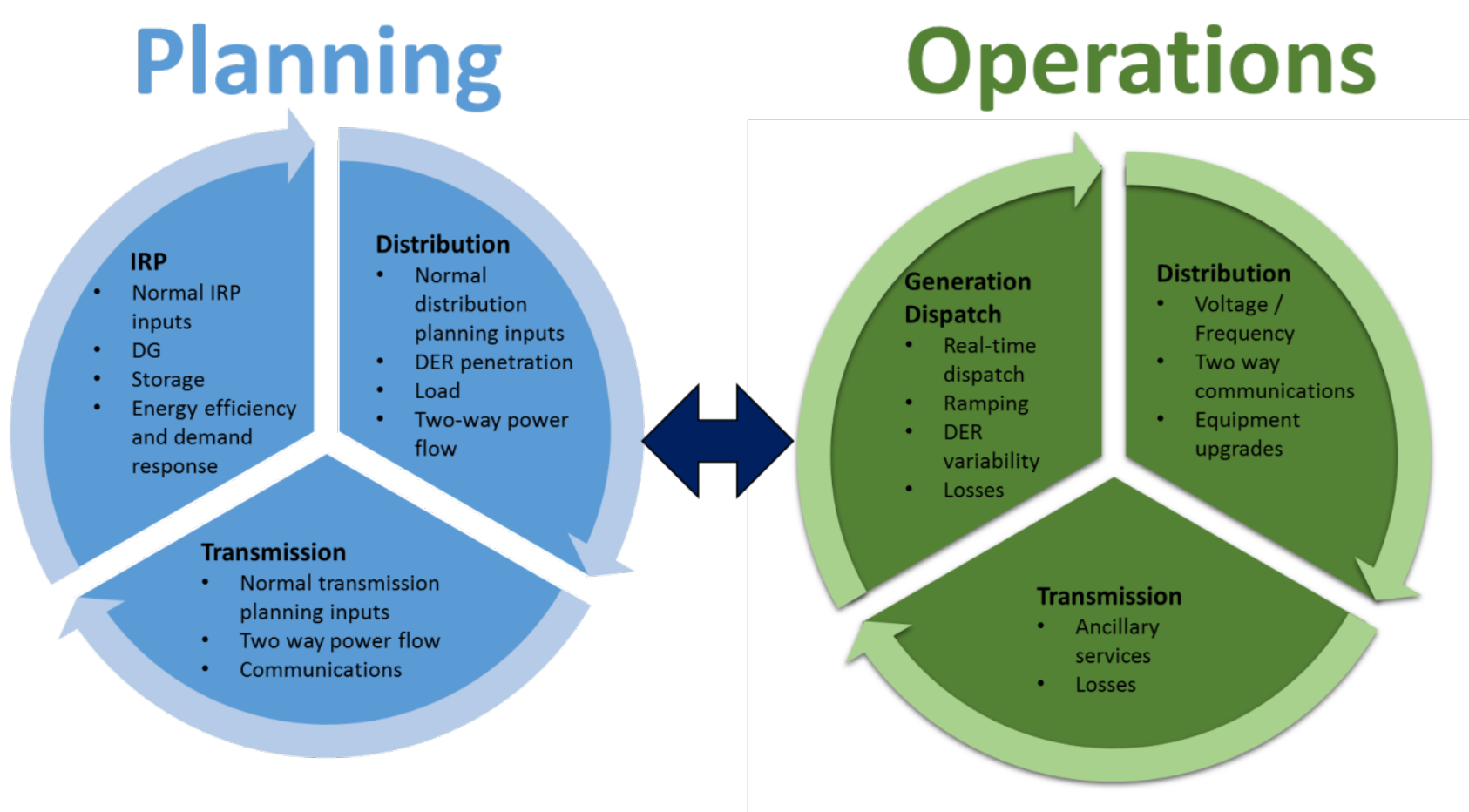

Figure 11. Integration of planning and operations across the flexible solar utility 


\section{Creating the Flexible Utility: Roadmaps and Signposts to the Future}

This section identifies metrics to track, data to monitor, market changes to watch, and Least Regrets Strategies that are expected to position most utilities to be ready for rapid growth of DER. The goal is to identify data collection and analysis activities that make sense now so that the utility can be prepared to proactively shape the future instead of just reacting to oncoming changes after the fact.

\section{Planning for Future Flexibility}

While the future of the utility industry is unclear, there are several steps that each utility can take over the next 5-10 years to be better prepared for whatever the future will hold. Transitioning from reactive to proactive is not something that can be accomplished overnight; rather, each utility will be reviewing planning, operational, and other changes in the context of their own markets, structures, and existing deployed technologies.

Utility survey respondents listed the following as the top three hurdles they expect to face in preparing for a rapid DER growth future:

1. Real-time data communications and IT infrastructure

2. Regulatory constraints and cost recovery

3. Internal organizational issues (staffing, training, etc.).

Culled from in-depth interviews, interactive discussions, and an online survey, the authors have distilled down the thoughts and ideas from a wide variety of utility personnel on how they could better address those hurdles and prepare their organizations for the future. Figure 12 describes specific Least Regrets Strategies for utilities to consider regardless of the future that materializes - across long-term planning, operations, IT/data/communications, utility interactions with customers, and utility business models. These consist of steps that utilities have identified as important and that should be considered and taken in the next several years to better leverage the direction of the industry - namely, to become "flexible" and adapt to the situations at hand. These are described in more detail in the following sections. 


\begin{tabular}{|c|}
\hline $\begin{array}{l}\text {-Develop supply- and demand-based distribution plans that roll up into the IRP } \\
\text { - Treat DERs as both fixed inputs and as selectable resources in the IRP } \\
\text { - Integrate Supply, Demand, Transmission, and Distribution planning processes into an overarching process } \\
\text { - Discuss a long-term distribution system investment plan with regulators }\end{array}$ \\
\hline $\begin{array}{l}\text { Operations } \\
\text { - Update standard equipment list to support distribution integration needs and infrastructure requirements } \\
\text { - Deploy advanced inverters system-wide } \\
\text { - Deploy sub-meters for distributed generation resources }\end{array}$ \\
\hline $\begin{array}{l}\text { IT, Data, \& Communications } \\
\text {-Develop a long-term IT, data, and communications plan that is tied into other planning processes } \\
\text { - Strategically deploy real-time communications infrastructure, AMI, etc. } \\
\text { - Move towards automated data management and analytics }\end{array}$ \\
\hline $\begin{array}{l}\text { Utility Interactions with Customers } \\
\text { - Create a "green team" for the customer call center } \\
\text { - Enable sophisticated customer energy portals } \\
\text { - Investigate new rate and pricing models } \\
\text { - Create routine customer workshops on energy consumption, new in-home technologies, and other topics } \\
\text { of interest }\end{array}$ \\
\hline $\begin{array}{l}\text { Utility Business Models } \\
\text { - Move towards holistic customer program design } \\
\text { - Create employee training initiatives around the changing grid } \\
\text { - Balance rate cases with multi-year rate reform plans }\end{array}$ \\
\hline
\end{tabular}

Figure 12. Least Regrets Strategies

\section{Long-Term Planning \\ Develop Supply- and Demand-based Distribution Plans that roll into the IRP}

Currently, utility distribution planning processes look out over relatively short timeframes and focus primarily on potential capital expenditures that will be required and that are not usually considered in transmission or integrated resource planning. Moreover, they do not look at customer adoption of DERs as a potential solution set; rather, that detail is often only considered after the fact during operational reviews of grid performance. While continued capital deployments for grid upgrades will certainly be required, utilities may want to consider DER technologies as viable options for deferring these costs. For example, the utility could identify a need on a specific feeder and, rather than moving forward with transformer upgrades, line reconductoring, or other typical processes, a new framework could allow load-sited generation, demand response, or similar activities to "compete" via the application of benefit/cost tests. For example, ConEd in New York City is actively considering this with their Brooklyn-Queens Initiative (ConEd 2014).

Regardless of the approach taken, these distribution plans could inform the utility and its regulators if it can also be integrated into the IRP process. While the timeframes do not often align, with distribution planning often covering shorter horizons like 5 years and IRPs addressing much longer-term horizons like 15 years, the level of granularity that could be leveraged from the distribution plan may be insightful when discussing supply and demand options in the context of the overarching IRP. 


\section{Treat DERs as both Fixed Inputs and as Selectable Resources in the IRP}

The majority of utilities today treat DERs as a net load impact, similar to how energy efficiency is treated (Sterling et al. 2013). Essentially, these demand-side resources are forecast and then taken out of the gross customer load shape; this revised load shape is then used in the IRP process. In some instances, these resources are not even explicitly broken out; rather, they are just assumed to be part of the load growth trend (in this instance, as a reason for growth to be lower than historic figures).

While treating DERs as a fixed and "known" value may make sense in some instances, ${ }^{7}$ it may be advisable to make them a fixed generation input rather than a net load impact. This would allow for better visibility into how the resource planning tools view DER impacts, and could allow for more seamless scenario planning. It would also provide better clarity on load forecasting. As a further step, utilities can consider allowing the resource planning tools to proactively select and optimize the level of penetration for each DER. With more accurate pricing information, this approach may lead to truly lowest cost plans and provide regulators with insight into how different DERs impact total portfolio costs (Sterling et al 2013).

\section{Integrate Supply, Demand, Transmission, and Distribution Planning Processes into an Overarching Process}

Not only are distribution plans often not included in the IRP process, but transmission plans may be left out as well. Some utilities conduct transmission planning as a completely separate function and the results become an input into the IRP, while others allow for transmission additions to be selectable choices in the IRP itself. Combining all three planning processes can provide regulators with a clearer vision of what the impending total capital requirements of the utility look like. While certainly more complicated, this form of universal optimization can also result in portfolios that are much more robust because they meet both least cost and least risk metrics.

\section{Discuss a Long-term Distribution System Investment plan with Regulators}

Regardless of which future state dominates the landscape, the distribution grid is likely going to have to evolve over time; only the speed of this transformation and the technology deployment decisions may vary. To facilitate these dialogues, utilities may want to consider creating meetings or forums with their regulators about distribution system capital requirements in general and the different technology choices that could be considered. Whether through a formal process or during routine discussions, these discussions can help propel dialogue about the advancing grid and the impacts for customers. These forums and the thoughts and insights provided therein can have a positive impact on how utilities begin rolling out system upgrades and how DERs play in that world - all of which are expected to be eventually included in future rate cases before regulators. Shifting the dialogue forward and talking about the "wheres", "whats", and "whys" can provide important education for all those involved in rate case review.

\footnotetext{
${ }^{7}$ Examples include when penetration is still low, or where incentives and associated budgets alone drive DER adoption.
} 


\section{Operations}

Update Standard Equipment list to meet Distribution grid Infrastructure Requirements

Utilities routinely maintain a list of standard equipment that can be purchased and installed on the system. For example, there are likely a handful of transformer specifications for deployment in a residential neighborhood, and the actual transformer installed will most likely be pulled from this specification list depending upon site requirements. Because of DERs impact on the changing grid, utilities might decide to proactively review their equipment lists more often, and to add new types of equipment as potential solutions, to ensure that they take advantage of the latest standards and technologies that support distribution integration needs.

\section{Deploy Advanced Inverters System-wide}

Related to the previous item, utilities could look at broad deployments of advanced inverter capabilities via the inclusion of these technologies into minimum interconnection standards. Advanced inverters can provide a variety of key functions, including reactive power support; voltage/frequency ride-throughs; modifications of ramp rates; and communications capabilities. Leveraging these capabilities at the edge of the grid can result in a more optimized deployment of rooftop solar and can result in more efficient capital deployment, as other distribution upgrades to manage power flows and voltages can be deferred or completely replaced by the inverter. In some instances, it may make sense for the utility itself to own the inverter as well (Davidovich and Sterling 2014).

\section{Deploy Sub-meters for DG Resources}

Not all utilities today require a separate production meter for behind-the-meter generation. As DER (and, specifically, rooftop solar) penetration increases, gaining access to the actual shape of those resource's production curves is increasingly important. Without sub-metering, utilities would be left estimating what the generation produced compared to other potential reasons for load fluctuations. If utilities consider including DERs as supply options in the IRP, gaining these hourly data becomes even more crucial. And by aligning actual known production against load, utilities would have even more visibility into each feeder's operating profile and have a higher likelihood of pinpointing what exactly was occurring on the grid during times of stress.

\section{IT, Data, and Communications \\ Develop a Long-term IT, Data, and Communications Plan that is Tied into Other Planning Processes}

As a corollary to the distribution plan, utilities may want to consider a broadly focused IT, data, and communications infrastructure planning process. This concept would integrate the needs and requirements being identified by all of the planning and operation organizations and seek to identify the IT backhaul and data management solution that best fits the needs of the utility. While this may occur on a piecemeal or siloed basis today, it is unlikely that many utilities perform cross-functional and cross-organizational discussions on why certain data is needed and what speed is demanded. Indeed, real-time data from the edge of the grid are very likely to be required for grid optimization in the future, and at a minimum, utilities will likely review those data after the fact to better identify system performance. This IT plan could also be incorporated into the comprehensive Supply, Demand, Transmission, and Distribution plan discussed earlier to show a broader picture of capital requirements to regulators. 
Strategically Deploy Near-Real-time Communications Infrastructure, AMI, etc.

As part of the advancement of the distribution system, utilities will be faced with a need for more frequent and more granular data. Utility AMI deployments are not universal, and while they may not be immediately justifiable from a cost perspective, AMI are expected to become a key resource for utilities as they analyze customer load shapes over time. The infusion of DERs envisioned in the rapid growth state may necessitate rate modifications, which become much more seamless using AMI. Further, the hourly data that can be gathered will be critical in both utility and consumer analytics. For the consumer specifically, the ability to learn about how hour-to-hour decisions within the home and how those decisions impact his/her electric bills can lead to better energy management. Without some form of AMI, the collection and display of this information becomes exceedingly difficult.

\section{Move Towards Automated data Management and Analytics}

The collection of hourly and sub-hourly data across tens of thousands of customers spread across hundreds of feeders could create unanticipated consequences associated with "Big Data." Taken all at once, this amount of information is completely overwhelming. To prevent these data from becoming effectively useless, the proper tools and applications that can mine, analyze, and present them in an understandable format - and quickly - will be useful. Dashboards, predetermined queries, and standardized data tables that pull the data on a routine basis can greatly enhance the usability of the information coming into the utility every day. By automating the analytics, this wealth of data can be leveraged in day-to-day operational decision making and also get pulled into planning processes.

\section{Utility Interactions with Customers}

Create a "Green team" for the Customer call Center

Several utilities today have taken the step of creating a special training program for select individuals within their customer call center. Known as the "green team," these representatives are provided with detailed training on renewable energy, energy efficiency, and other customer similar programs. When a customer calls wanting to discuss any of these types of issues, they are immediately routed to the green team, who are more capable of answering customer questions about their energy options. This leads to a better overall customer experience because they are not forced to wait in queue behind other unrelated customer questions or concerns, and they receive direct information in a conversational format.

For utilities considering the creation of a green team, it is important to understand the metrics with which call centers are measured. For example, many customer care centers track the length of wait time and length of call time for each incoming call. On the latter, the goal is often to handle each customer's issue as quickly as possible because most customers do not enjoy these experiences at all, and most value getting their questions resolved with minimal time expended. For green team calls, though, it is highly likely that customers are specifically looking for a more detailed conversation. Excluding the green team calls from the call length metric can provide a strong statement to the green team members that the customer experience is critical for these calls. 


\section{Enable Sophisticated Customer Energy Portals}

Over the past several years, utilities have been updating their websites to include customer portals where historical billing and usage information can be found. With the advent of AMI, utilities can present customers with very granular information on usage by showing the hour-tohour consumption changes. Some utilities take this one step further and show the impact of different rate plans on the customer's energy bill. These types of activities could become very important over time, particularly as customers are faced with DER options from both the industry and the utility (in the form of rooftop solar, other generation technologies, demand response programs, and other utility programs).

A potential strategy for better engaging with customers via the Web portal is to provide a series of calculators and estimators for consumers. In essence, the utility would leverage customerspecific hourly data to show how different rates, technologies, and load management strategies impact their hourly consumption, and ultimately, the bill. From a technology perspective, one example would be a solar calculator that showed before and after energy profiles with cost estimations. Some utilities already take this step, at least for customer-owned solar; PG\&E has a solar calculator to estimate the cost of installing solar and the bill savings (PG\&E 2015). In theory, though, this could be used for any type of solar product (leases, PPAs, community solar, etc.). Taking this one step further, utilities could enable an interface where customers could identify during which hours specific household appliances run on a specific day or on a typical day, and receive feedback on maximizing savings on their rates.

Driving customers to gain a better understanding of how their actions within the home translate to their bills, and providing tools to understand different technologies and usage patterns, can increase trust and create a more engaged consumer.

\section{Investigate new rate and Pricing Models}

While some utilities currently leverage time-of-use rates and/or demand charges for residential customers, by and large most customers today are still served on a flat rate or an inclining block rate (where the more you use, the more expensive it becomes). Utilities may consider investigating how to change the way rates are designed so that customers get more accurate price signals, not only based on when they use energy, but also how they use it. Moving towards dynamic pricing regimes like real-time pricing, critical peak pricing, peak time rebates, and other models will require further investigation as they may not be appropriate in all circumstances.

\section{Create Routine Customer Workshops on Energy Consumption, new In-home Technologies, and Other Topics of Interest}

During the working session at SEPA's Utility Solar Conference, one participant shared how their ${ }^{8}$ utility holds routine customer workshops about solar across the utility territory. The benefits are that customers learn this information from a trusted source, and it provides the opportunity to provide better service to customers interested in relatively new technologies like solar. This same concept could be leveraged for informal and formal discussions on a variety of issues across all DERs. Customer workshops could be held on solar, storage, demand response, electric vehicles, and other topics of interest at different community centers or other meeting

\footnotetext{
${ }^{8}$ The plural is used because participants were promised anonymity.
} 
locations, and provide the utility with a chance to both educate the customer on different technologies while also learning customer interests directly from them.

Separately, similar sessions could be held with local industry - from contractors to developers. This would create a forum for the utility to educate these companies on existing and planned programs, standards, requirements, and regulations, and provide an opportunity for constructive feedback on potential areas of improvement in utility processes and procedures.

Creating a bi-directional flow of information, however formal or informal, can provide the utility with much needed information on customer interests and how to better serve their needs.

\section{Utility Business Models}

\section{Move Towards Holistic Customer Program Design}

Many utilities offer a host of program choices to their customers, from energy efficiency to demand response, net energy metering to electric vehicles. And even within those categories, sometimes dozens of options exist. For example, energy efficiency programs may be broken out specifically to new air conditioning, window retrofits, shade screens, shade trees, etc. But in many cases, these programs sit individually with their own budgets and targets, and are not considered as part of a broader offering to the consumer. The one real exception is home energy audits that are more comprehensive in nature, but still only focus on efficiency measures and fail to look at other choices.

The consumer, however, is likely considering multiple options to improve his/her home's energy equation - and those choices may not align with how the utility presents choices. To combat this potential issue of perspective, utilities may want to look at more holistic program design alternatives that provide packaged approaches for customer consideration. For example, demand response could be paired with a solar program to better align customer energy consumption with when the sun is shining. One innovative example is the community solar program at SteeleWaseca Cooperative Electric, which provides an option for a discounted panel in exchange for participation in a water heater program (SWCE 2015). Utilities could learn more if they looked at the interplay between all of the resources and identify places where synergies exist.

\section{Create Employee Training Initiatives Around the Changing Grid}

As the energy system evolves, so will the skill sets and training required for the utility employee. For distribution engineers, a better understanding of DER technology specifications and capabilities will likely be necessary. Linemen will probably need training on DER interconnections to better perform their duties safely. Management teams will need specialized training as well to best lead and transform with the workforce of the future. These and similar requirements are likely to permeate across all business units over time, changing how utilities look to staff internally (Edge et al 2014). One strategy for addressing this was discussed above the green team - so that different aspects of the utility business can get specialized training. Additionally, the utility could work with local community colleges and trade schools on specialized training and education programs that can be leveraged for the next generation of utility employee. 


\section{Balance rate Cases with Multi-year rate Reform Plans}

Virtually all of the items discussed as Least Regrets Strategies are most likely to ultimately manifest themselves in a rate case with the utility's regulators. Rate cases are often based on historical test years, adjusted for known impending activities. Even in jurisdictions that utilize future test years, the processes may not be optimal for considering long-term broad investment strategies and requirements. This makes sense because planning activities are disassociated from rate-setting precisely because the future is uncertain; however, these forums may be the most appropriate place to lay out how rates may need to change over time to accommodate the changing environment of the electric industry and the utility-customer transaction. While it is important to consider the future state, it is also important to consider outlining incremental changes to consider over time as different triggers are hit. For example, as customer usage data become more transparent through energy portals and as rate design choices become easier to understand, utilities may want to consider stepping into real-time or time-of-use pricing for residential customers as the standard rate offer. Providing these forward-thinking ideas to regulators and laying out multi-year plans can provide the industry and other stakeholders with a vision for the future and how to adapt in a gradual manner as opposed to changing rapidly overnight.

\section{Identifying Signposts}

In order to successfully build upon the Least Regrets Strategies, it is important to monitor specific signposts. From very broad industry trends down to very granular customer data (see Figure 13), these signposts are meant to provide signals to the utility about the direction the industry is going as well as the speed with which it is adapting. Signposts represent key indicators of (1) the direction of the transformation between the current state and the future of the energy sector and (2) the speed with which that transformation may be taking place. Signposts exist at the most macro (industry) level and micro (customer) levels.
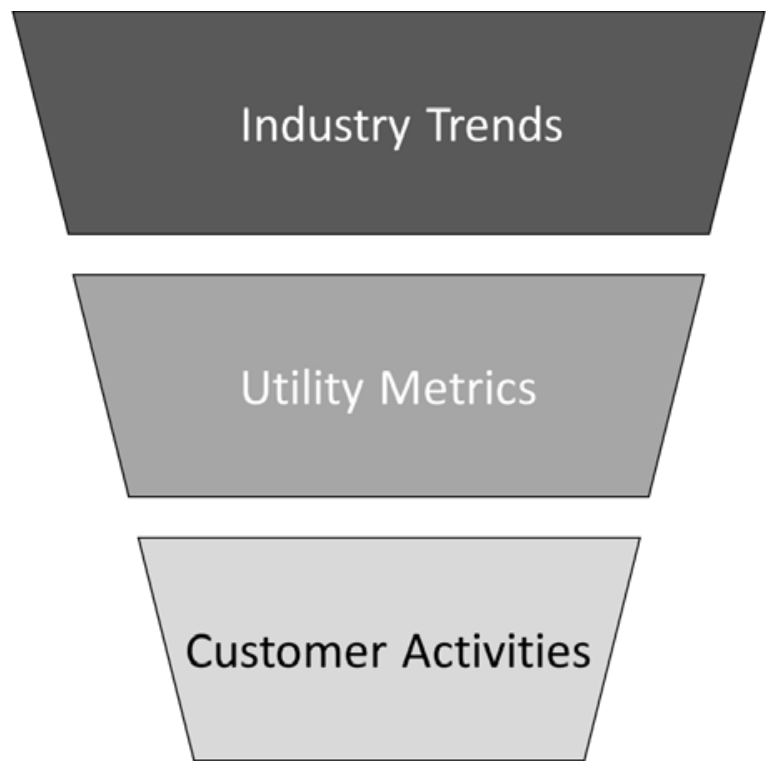

Figure 13. Granularity of signposts 
Understanding what to monitor and why can provide utilities with a solid framework for understanding how and when to roll out changes to their business model, planning processes, and operations. The authors have identified a series of signposts from our experience, discussions with utilities, and the workshop held at the SEPA Utility Solar conference in Table 3. Collecting and analyzing data on these signposts may provide early signals on the speed and timing of DER adoption. As shown, they are broken down into broader DER industry trends, specific utility metrics, and customer activities. While not every utility needs to monitor all of these signposts, capturing and reviewing data from at least one metric from the three categories on a routine basis (at least once a year, if not more) will provide a base understanding about how the market is changing and the role that DER could play going forward. 
Table 3. Signposts

\begin{tabular}{|c|c|c|}
\hline $\begin{array}{l}\text { Granularity } \\
\text { of Signpost }\end{array}$ & Signpost & Reason to Monitor \\
\hline \multirow{8}{*}{$\begin{array}{l}\text { Industry } \\
\text { Trends }\end{array}$} & $\begin{array}{l}\text { National } \\
\text { penetration of } \\
\text { DERs }\end{array}$ & Provides insight into the growth and adoption rates of technologies \\
\hline & DER cost trends & $\begin{array}{l}\text { Provides insight into which technologies are becoming economic on a } \\
\text { national basis }\end{array}$ \\
\hline & $\begin{array}{l}\text { Utility } \\
\text { technology } \\
\text { advancements }\end{array}$ & $\begin{array}{l}\text { New technologies that can be deployed on the transmission } \\
\text { distribution systems, or incorporated into generation fleets, may } \\
\text { change how utilities plan and operate going forward }\end{array}$ \\
\hline & $\begin{array}{l}\text { Fuel price } \\
\text { forecasts }\end{array}$ & $\begin{array}{l}\text { Natural gas price fluctuations can impact the viability of DERs from a } \\
\text { utility planning perspective }\end{array}$ \\
\hline & $\begin{array}{l}\text { National tax } \\
\text { and } \\
\text { environmental } \\
\text { policy issues }\end{array}$ & $\begin{array}{l}\text { Tax credits, environmental regulations, and other national policy } \\
\text { activities can change how utilities view customer-sited DERs }\end{array}$ \\
\hline & $\begin{array}{l}\text { Utility electrical } \\
\text { standards }\end{array}$ & $\begin{array}{l}\text { IEEE, UL, and others are modifying standards related to many resources } \\
\text { (e.g., inverters), which may need to be adopted by utilities }\end{array}$ \\
\hline & $\begin{array}{l}\text { Federal } \\
\text { standards }\end{array}$ & $\begin{array}{l}\text { The Federal Energy Regulatory Commission (FERC) and the North } \\
\text { American Electric Reliability Corporation (NERC) often consider and } \\
\text { impose new standards on the utility industry related to maintaining a } \\
\text { competitive environment while supporting safe and reliable service }\end{array}$ \\
\hline & $\begin{array}{l}\text { Cyber-security } \\
\text { standards }\end{array}$ & $\begin{array}{l}\text { The creation of thousands of entry points on the distribution system, } \\
\text { via AMI and other technologies, raises the risk for cyber-security; } \\
\text { maintaining resiliency will be key going forward }\end{array}$ \\
\hline \multirow{4}{*}{$\begin{array}{l}\text { Utility } \\
\text { Metrics }\end{array}$} & $\begin{array}{l}\text { Utility-specific } \\
\text { DER cost curves } \\
\text { and retail rates }\end{array}$ & $\begin{array}{l}\text { National pricing trends translated to the utility's territory and } \\
\text { compared against customer value propositions can help the utility } \\
\text { understand DER economics }\end{array}$ \\
\hline & $\begin{array}{l}\text { Peer utility DER } \\
\text { penetration } \\
\text { levels }\end{array}$ & $\begin{array}{l}\text { DER adoption levels at neighboring and/or similarly situated utilities } \\
\text { can provide insight into when DER adoption may grow }\end{array}$ \\
\hline & $\begin{array}{l}\text { Feeder-specific } \\
\text { characteristics }\end{array}$ & $\begin{array}{l}\text { The health and reliability of the grid is key, and tracking and conducting } \\
\text { analytics on feeder-specific characteristics such as power flows, voltage } \\
\text { and frequency fluctuations, and other key metrics can signal when to } \\
\text { deploy new technologies, standards, and protocols }\end{array}$ \\
\hline & $\begin{array}{l}\text { Interconnection } \\
\text { request volume }\end{array}$ & $\begin{array}{l}\text { The simplest metric of DER adoption, monitoring interconnection } \\
\text { request volume allows for trend analysis to determine penetration } \\
\text { uptake }\end{array}$ \\
\hline \multirow{2}{*}{$\begin{array}{l}\text { Customer } \\
\text { Activities }\end{array}$} & $\begin{array}{l}\text { Energy portal } \\
\text { views }\end{array}$ & $\begin{array}{l}\text { As customers begin interacting and viewing their consumption } \\
\text { information more frequently, they may be interested in DER adoption } \\
\text { and/or new energy offerings from the utility. Mobile apps that are } \\
\text { engaging and informative may increase views. }\end{array}$ \\
\hline & $\begin{array}{l}\text { Load shape } \\
\text { patterns }\end{array}$ & $\begin{array}{l}\text { Monitoring the changes in hourly load shapes over the long term can } \\
\text { indicate when customers have adopted DERs that don't require utility } \\
\text { notification (e.g., electric vehicles) }\end{array}$ \\
\hline
\end{tabular}




\section{Developing a Roadmap for the Future}

Each utility is at a different point with regards to their current generation mix, the type (and age) of assets deployed on the distribution system, how integrated their planning processes are, and how many DERs have been adopted throughout their territory. And not every utility will end up in the same place 15 years from now. But understanding the changing landscape as those changes occur, and building in the flexibility to adapt to the changing environment, will result in a healthier, less risky utility over the long term. The Least Regrets Strategies identified in this paper are not for every utility, but many of the ideas can provide a solid foundation for being prepared to address new challenges that result from DERs in the future. 


\section{Conclusion and Next Steps}

\section{Conclusion}

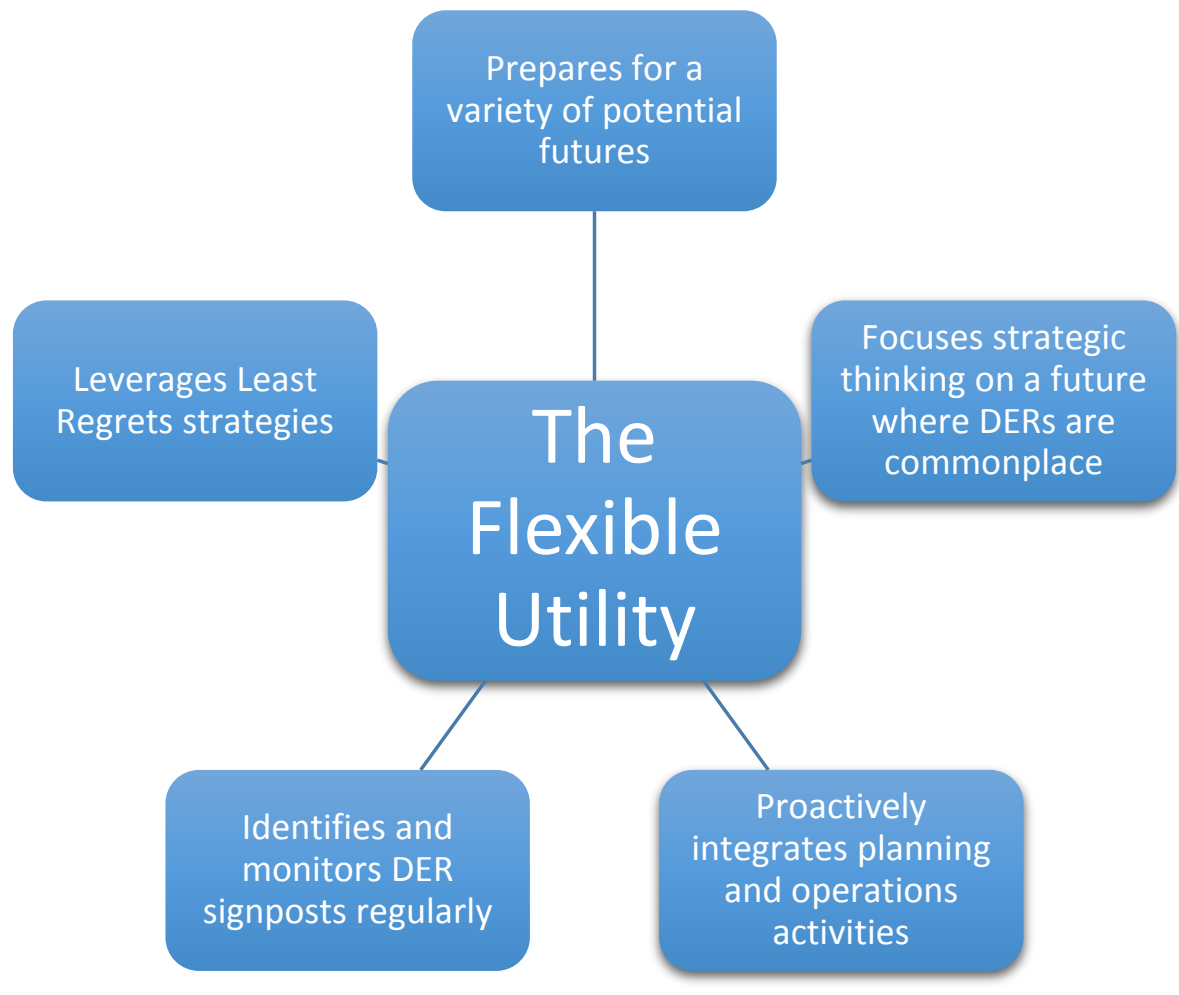

Figure 14. Creating a flexible utility

Changes at the distribution level have the potential to challenge utility planning and operations in ways it has never needed to react before. This could include everything from the introduction of two-way power flow to more robust communication and data acquisition systems, as well as other impacts on generation, transmission and distribution planning and operations procedures, systems, protocols, and resources. Figure 14 summarizes the activities that a flexible utility does to prepare for an influx of DERs in the future:

- Be prepared for a variety of potential futures, particularly for one where DERs proliferate. While it is not clear how much the electric sector will change and exactly which technologies will be implemented when, and how quickly, it is becoming clear that transformation seems inevitable between more economic enabling technologies and customer demands. Preparing for a wide variety of future directions may help utilities remain nimble. Considering the impacts of increased DER and the way the utility needs to prepare to be ready to collect new data, analyze new metrics, incorporate new technologies, and create new pathways to successfully assimilate all the changes will likely be critical for success.

- Update planning and operations activities--before DER becomes an issue. Planning processes are occurring all the time, but are not highly integrated. Modifying existing procedures to better assimilate distribution, transmission, and supply planning into a more symbiotic process will be an extremely time consuming and, unfortunately, 
daunting task. As such, it may be too late to wait until DER begins to affect the electric system, because by the time planning changes are implemented, DER could increase to high enough penetration levels to have significant impacts on utility operations. Taking action now to update planning processes to better monitor and incorporate information about DER could help any utility remain flexible enough to deal with this transformation as it evolves. In other words, the utility that takes action before DER is notable in impacting operations, and that updates planning and operations processes, will probably be ahead of the changes and in the best position to react to a myriad of potential outcomes successfully.

- Identify DER signposts and monitor them regularly. It may be impossible to predict how the electric sector will transform. However, it is possible to collect and monitor data on a number of signposts that cover broader DER industry trends, specific utility metrics, and customer activities. By checking on these signposts regularly and comparing historical data, it will become clear which emerging disruptions are changing most quickly. Doing so could help a utility be better prepared for how their electric system is changing and the potential actions needed to respond.

- Prepare for the multitude of impacts to utility planning and operations using Least Regrets Strategies. The introduction of solar and other DER technologies is expected to impact a variety of key internal operations, including long-term planning, operations, IT and communications, utility interactions with customers, and utility business models. Additionally, there are more granular impacts to the way a utility plans and performs its operations. Thoughtfully considering potential impacts and preparing for additional needs, including new resources and staffing, and laying a foundation to be ready for various possibilities will help utilities be flexible enough to deal with a more rapid transformation than experience historically_while maintaining reliability.

\section{Next Steps}

Next steps and future analysis could cover a variety of activities to build on those outlined in this report. These are suggested as opportunities for utilities, regulators, and other policymakers and analysts to better understand the current situation and the implications across a variety of future directions (including but not limited to the Rapid Growth of DER future direction).

- Localized analysis. The first step is to analyze each future direction in detail across a wide variety of parameters at a particular location. This would include a deeper analysis of the generation mix; both the incremental supply changes and the resulting overall generation mix. Examining the generation mix will highlight and help increase understanding of the impact of actions taken, or even those proposed. Analyzing the future directions in detail would also include much more fidelity on the level of flexibility the system would require to successfully address the changing generation mix on system operations, and would identify specific changes needed for both transmission and distribution to maintain reliability.

- Cost-benefit analysis. Additionally, the benefits and costs of different futures could be analyzed and compared to business-as-usual. Calculating the relative costs and benefits is an important metric to track; as technology costs and installation costs change and the relative benefits that new technologies provide to the electric system are valued in the 
market, it is expected that the cost of alternative future directions will begin to close in on the cost of replacing existing resources with the same type of resources. In other words, new technologies might be able to compete with or even beat the economics of continuing to follow business-as-usual practices. To the extent that risk and uncertainty are included in the equation, the potential for stranded assets, carbon policies, or other considerations could tip the balance away from BAU earlier than anticipated. Finally, emissions impacts of each future direction could be captured and quantified - not just for carbon emissions, but perhaps other emissions as well (potentially $\mathrm{Hg}$ or criteria pollutants).

- DER System Impact Analysis. There are many incremental analysis activities needed to truly understand the impact of DER on the electric system; the Least Regret strategies and accompanying activities identified in the report are just a start. Because DERs are expected to transform the electric sector and the utility business model more than any other future direction, gathering additional data and performing analysis will be critical for tracking the impact of DER on specific utilities, their business models, and shareholder returns. For example, the level of granularity required will increase if markets increase fidelity down to 5-min intervals. And to the extent that DER reaches higher penetration levels, knowledge about ramping impacts and market valuations become more important. Overall, the amount of data needed for collection and analysis will increase and will require new software, more powerful computers, and more analysts to review the impacts.

- Aggregate lessons learned. Outside of the additional analysis on any particular jurisdiction, there are broader analyses needed to better understand the impact of DER. These analyses could include identifying German and Hawaiian lessons learned and how they can inform other locations - including ways to upgrade payments, calculate the value of services, etc.

- Build a flexibility supply curve. Another DER analysis opportunity is to explore incorporation of a system asset that can increase flexibility and allow for more optimal use of existing generation, storage, more optimal transmission build-out, increased responsive loads, and advanced system controls. By building a supply curve of valuation/mitigation measures, and analyzing business models and market rules against these measures, utilities can better understand the impact of DER and actions they can take (and their costs) to mitigate changes in the electric system. Cost and emissions impacts could also be quantified. Finally, the benefits of coordinating the response to rapid DER growth beyond a utility's jurisdiction to states and regions, could decrease customization and make it easier for utilities and the DER providers to seamlessly integrate their programs, thus decreasing the overall cost of implementation. In other words, planned coordination could lead to a more efficient response to a rapid DER growth future.

- Pilot project implementation. Further, pilot projects for transactional energy can be pursued that increase communication between the generating consumer (or prosumer) and the utility/system. Increased communication is seen as a critical component to the successful transition to a future with rapid growth of DER; therefore, communication needs will be important to address. And for the DER future in particular, considering the 
ways that a centralized distribution system operator could be structured, who would participate, and how could help illuminate the possibilities for utilities and other market players.

- Decision tools for risk and uncertainty. Lastly, it could also be helpful to identify ways to incorporate risk and uncertainty factors into decision-making, particularly for state regulations and competitive market rules. Possible analyses could include consider policies and regulations that identify and capture risk, make risk/uncertainty transparent, and incentivize optimized generation, transmission and distribution simultaneously. Another analysis could review and refine competitive market rules and IRP frameworks to include performance metrics - the inclusion of which could reduce market uncertainty. Finally, risks can be considered from a variety of perspectives since these changes will impact different stakeholders in various ways.

While it is impossible to predict the future, it is possible to prepare for a variety of possible futures. It appears that DER will expand as technology costs come down and consumers demand new options; since this future has the greatest impact on utility planning and operations, early preparation can help position a utility to be a flexible utility - one that is ready to take on new challenges associated with the changing electric system. 


\section{References}

Aggarwal, S., and E. Burgess. 2014. New Regulatory Models. Prepared for the State-Provincial Steering Committee on Regional Electric Power Cooperation. March 2014. Accessed: Jan 2015. http://americaspowerplan.com/wp-content/uploads/2014/03/NewRegulatoryModels.pdf

Bird, L., J. Cochran, and X. Wang. 2014. Wind and Solar Energy Curtailment: Experience and Practices in the United States. Technical Report. Golden, CO: National Renewable Energy Laboratory. NREL/TP-6A20-60983. 58 pp. http://www.nrel.gov/docs/fy14osti/60983.pdf

Bird, L., M. Milligan, and D. Lew. 2013. Integrating Variable Renewable Energy: Challenges and Solutions. Technical Report. Golden, CO: National Renewable Energy Laboratory. NREL/TP-6A20-60451. http://www.nrel.gov/docs/fy13osti/60451.pdf

Bird, L., and M. Milligan. 2012. "Lessons from Large-Scale Renewable Energy Integration Studies." (Preprint). Paper presented at the 2012 World Renewable Energy Forum, Denver, Colorado, May 13-17. Golden, CO: National Renewable Energy Laboratory. NREL /CP-6A2054666. http://www.nrel.gov/docs/fy12osti/54666.pdf

Blarke, M., and B. Jenkins. 2013. "SuperGrid or SmartGrid: Competing Strategies for LargeScale Integration of Intermittent Renewables?” Energy Policy 58:381-390. Accessed Aug 2014. doi:10.1016/j.enpol.2013.03.039

Bloomberg New Energy Finance. 2014. "Fight, Flight or Adapt: How are US Utilities Coping with Distributed PV?" New York, New York: BNEF US Solar Research Note. (By subscription.) http://about.bnef.com/

Cochran, Jaquelin, Lori Bird, Jenny Heeter, and Douglas Arent. 2014a. "Integrating Variable Renewable Energy in Electric Power Markets: Best Practices from International Experience." Chapter VI. The ICER Chronicle pp. 25-31. Accessed July 2015. http://www.icerregulators.net/portal/page/portal/ICER_HOME/publications_press/ICER_Chronicle/ICER\%20C hronicle\%20Edition\%202.pdf

Cochran, Jaquelin, Mackay Miller, Owen Zinaman, Michael Milligan, Douglas Arent, Bryan Palmintier, Mark O’Malley, Simon Mueller, Eamonn Lannoye, Aidan Tuohy, Ben Kujala, Morten Sommer, Hannele Holttinen, Juha Kiviluoma, and S.K. Soonee . 2014b. Flexibility in 21st Century Power Systems. 21st Century Power Partnership. Technical Report. Golden, CO: National Renewable Energy Laboratory. NREL/TP-6A20-61721.

May. http://www.nrel.gov/docs/fy14osti/61721.pdf

Cochran, J., L. Bird, J. Heeter, and D.J. Arent. 2012. Integrating Variable Renewable Energy in Electric Power Markets: Best Practices from International Experience. Technical Report. Golden, CO: National Renewable Energy Laboratory. NREL/TP-6A2053732. http://www.nrel.gov/docs/fy12osti/53732.pdf 
Coddington, Michael, Ben Kroposki, and Barry Mather. 2014. "Defining PV Penetration." Internal presentation at the National Renewable Energy Laboratory. January.

Commonwealth Scientific and Industrial Research Organisation (CSIRO). 2013. Change and Choice: The Future Grid Forum's Analysis of Australia's Potential Electricity Pathways to 2050. https://publications.csiro.au/rpr/download?pid=csiro:EP1312486\&dsid=DS13

Consolidated Edison (ConEd). 2014. "Request for Information: Innovative Solutions to Provide Demand Side Management to Provide Transmission and Distribution System Load Relief and Reduce Generation Capacity Requirements." Issued July 15, modified March 31, 2015. Accessed July 2015. Full RFI

text: http://www.coned.com/energyefficiency/pdf/Demand_Management_Project_SolicitationRFI-Reopen ver2.pdf Full

program: http://www.coned.com/energyefficiency/competitive_solutions_opportunities.asp

Cory, Karlynn, and Alexandra Aznar. 2014. "Informing Electricity Systems of the Future: Key Analysis Needs." Electricity Journal 27:73-82. NREL Report No. JA-6A20-

62517. http://dx.doi.org/10.1016/j.tej.2014.10.007

Davidovich, Ted, and John Sterling. 2014. Unlocking Advanced Inverter Technology: Roadmap to a Future of Utility Engagement and Ownership. Solar Electric Power

Association. http://www.solarelectricpower.org/unlocking-advanced-inverter-functionality.aspx

Denholm, P., R. Margolis, B. Palmintier, C. Barrows, E. Ibanez, L. Bird, and J. Zuboy. 2014. Methods for Analyzing the Benefits and Costs of Distributed Photovoltaic Generation to the U.S. Electric Utility System. Technical Report. Golden, CO: National Renewable Energy Laboratory. NREL/TP-6A20-62447. http://www.nrel.gov/docs/fy14osti/62447.pdf

Edge, Ryan, and Mike Taylor. 2014. "Benchmarking Utility Organizational Structures: How Renewable Energy is Reshaping the Utility Hierarchy." Solar Electric Power Association. Accessed June 2015. https://www. solarelectricpower.org/benchmarking-utility-organizationalstructures-how-renewable-energy-is-reshaping-the-utility-hierarchy.aspx

Edge, Ryan, Mike Taylor, Nadav Enbar, and L. Rogers. 2014. Utility Strategies for Influencing the Locational Deployment of Distributed Solar. Solar Electric Power Association (SEPA) and Electric Power Research Institute

(EPRI). https://www.solarelectricpower.org/media/224388/Locational-Deployment-ExecutiveSummary-Final-10-3-14.pdf

Electric Power Research Institute (EPRI). 2015. “The Integrated Grid.” Accessed Jun 2015. http://integratedgrid.epri.com/

GE Digital Energy, Analysis Group. 2013. Results-Based Regulation: A Modern Approach to Modernize the Grid. Regulatory White Paper. GE Digital Energy. Accessed July 7, 2015. https://www.gedigitalenergy.com/regulation/ 
Hand, M.M., S. Baldwin, E. DeMeo, J.M. Reilly, T. Mai, D. Arent, G. Porro, M. Meshek, and D. Sandor. 2012. Renewable Electricity Futures Study (Entire Report). 4 vols. Golden, CO: National Renewable Energy Laboratory. NREL/TP-6A20-52409. Accessed Aug 2014. http://www.nrel.gov/analysis/re futures/

Harvey, Hal, and Sonia Aggarwal. 2013. Overview: Rethinking Policy to Deliver a Clean Energy Future. America's Power Plan. (Curated by Energy Innovation). 36 pp. Accessed June 21, 2015. http://americaspowerplan.com/wp-content/uploads/2013/09/APP-OVERVIEWPAPER.pdf

Hawaiian Public Utility Commission (HI PUC). 2014. Exhibit A: Commission's Inclinations on the Future of Hawaii's Electric Utilities. Accessed Feb 2015. http://puc.hawaii.gov/wpcontent/uploads/2014/04/Commissions-Inclinations.pdf

Heeter, J., R. Gelman, L. Bird. 2014. Status of Net Metering: Assessing the Potential to Reach Program Caps. Technical Report. Golden, CO: National Renewable Energy Laboratory. 46 pp. NREL/TP-6A20-61858. http://www.nrel.gov/docs/fy14osti/61858.pdf

Joe, Benson, Mon Hong, and John Sterling. 2015. Impact of High Solar and Energy Storage Levels on Wholesale Power Markets. Black \& Veatch / Solar Electric Power Association. 31 pp. http://bv.com/docs/default-source/reports-studies/solar-and-energy-storage-impacts-onwholesale-power-markets.pdf?sfvrsn $=4$

Jones, L., ed. 2014. Renewable Energy Integration: Practical Management of Variability, Uncertainty, and Flexibility in Power Grids. Academic

Press. http://scitechconnect.elsevier.com/wp-content/uploads/2014/06/Sample_FM RenewableEnergy-Integration-2.pdf

Kind, Peter. 2013. Disruptive Challenges: Financial Implications and Strategic Responses to a Changing Retail Electric Business. Prepared by Energy Infrastructure Advocates for Edison Electric Institute. http://www.eei.org/ourissues/finance/documents/disruptivechallenges.pdf

Lehr, Ronald. 2013. New Utility Business Models: Utility and Regulatory Models for the Modern Era: America's Power Plan. http://americaspowerplan.com/wpcontent/uploads/2013/10/APP-UTILITIES.pdf

McLaren, Joyce, Carolyn Davidson, Lori Bird, and John Miller. (Forthcoming). Impact of Rate Design Alternatives on Residential Solar Customer Bills: Increased Fixed Charges, Minimum Bills and Demand-based Rates. Technical Report. Golden, CO: National Renewable Energy Laboratory. NREL/TP-6A20-64850. http://www.nrel.gov/docs/fy15osti/64850.pdf .

Mendelsohn, Michael, Claire Kreycik, Lori Bird, Paul Schwabe, and Karlynn Cory. 2012. The Impact of Financial Structure on the Cost of Solar Energy. Technical Report. Golden, CO: National Renewable Energy Laboratory. NREL/TP-6A2053086. http://www.nrel.gov/docs/fy12osti/53086.pdf 
Miller, Mackay, and Sadie Cox. 2014. Overview of Variable Renewable Energy Regulatory Issues. Technical Report. Golden, CO: National Renewable Energy Laboratory. NREL/TP6A20-61350. http://www.nrel.gov/docs/fy14osti/61350.pdf

New York State Department of Public Service. 2015. "Reforming the Energy Vision." Staff Report. http:/www3.dps.ny.gov/W/PSCWeb.nsf/All/CC4F2EFA3A23551585257DEA007DCF E2?OpenDocument

New York State Department of Public Service (NYS DPS). 2014. "Reforming the Energy Vision." Staff Report and Proposal. Case 14-M-0101. April

24. http://www3.dps.ny.gov/W/PSCWeb.nsf/All/C12C0A18F55877E785257E6F005D533E?Ope nDocument\#RULINGS

Newcomb, James; Virginia Lacy; and Lena Hansen. 2013. New Business Models for the Distribution Edge: The Transition from Value Chain to Value Constellation. Rocky Mountain Institute's Electricity Innovation Lab.

April. http://www.rmi.org/New_Business_Models_Download

Pacific Gas and Electric (PG\&E). 2015. "Solar Calculator." PG\&E website. Accessed July 2015. http://www.pge.com/en/myhome/saveenergymoney/solar/solarcalc.page

Porter, Kevin, C. Mudd, S. Fink, J. Rogers, L. Bird, L. Schwartz, M. Hogan, D. Lamont and B. Kirby. 2012. Meeting Renewable Energy Targets in the West at Least Cost: The Integration Challenge. Prepared by Regulatory Assistance Project for Western Governors' Association. 144 pp. http://www.westgov.org/component/docman/doc_download/1610-meeting-renewableenergy-targets-inthe-west-at-least-cost-the-integration-challenge-full-report?Itemid

Propper, Steve. 2015. Alternate Utility Revenue Streams: Expanding Utility Business Models at the Grid Edge. GTM Research. http://www.giiresearch.com/report/gm330466-alternate-utilityrevenue-streams-expanding.html

Richter, Mario. 2013. "Business Model Innovation for Sustainable Energy: German Utilities and Renewable Energy.” Energy Policy 62:1226-1237. doi:10.1016/j.enpol.2013.05.038

Richter, Mario. 2012. "Utilities’ Business Models for Renewable Energy: A Review." Renewable and Sustainable Energy Reviews 16: 2483-2493. Accessed June 21, 2015. doi:10.1016/j.rser.2012.01.072

Satchwell, Andrew, Peter Cappers, Lisa Schwartz, and Emily Martin Fadrhonc. 2015. A Framework for Organizing Current and Future Electric Utility Regulatory and Business Models. Berkeley, CA: Lawrence Berkeley National Laboratory. LBNL181246. http://emp.lbl.gov/sites/all/files/lbnl-181246.pdf

Small, Forrest, and Lisa Frantzis. 2010. The 21st Century Electric Utility: Positioning for a Low-Carbon Future. Prepared by Navigant Consulting for Ceres. July 
2010. http://www.ceres.org/resources/reports/the-21st-century-electric-utility-positioning-for-alow-carbon-future-1

Solar Electric Power Association (SEPA). 2014. “A Blank Slate for a New Energy Market.” The 51st State Challenge. http://www.sepa51.org/

Steele-Waseca Cooperative Electric (SWCE). 2015. Community Solar: Frequently Asked Questions. SWEC Solar Wise and the Sunna Project Program Document. Accessed July 2015. http://swce.com/documents/CommunitySolarFAQ061215.pdf

Sterling, John, Joyce McLaren, Mike Taylor, and Karlynn Cory. 2013. Treatment of Solar Generation in Electric Utility Resource Planning. Technical Report. Golden, CO: National Renewable Energy Laboratory. NREL/TP-6A2060047. http://www.nrel.gov/docs/fy14osti/60047.pdf

Taylor, M., J. McLaren, K. Cory, T. Davidovich, J. Sterling, and M. Makhyoun. 2015. Value of Solar: Program Design and Implementation Considerations. Technical Report. Golden, CO: National Renewable Energy Laboratory. 84 pp. NREL/TP-6A2062361. http://www.nrel.gov/docs/fy15osti/62361.pdf

Zinaman, O., M. Miller, A. Adil, D. Arent, J. Cochran, R. Vora, S. Aggarwal, M. Bipath, C. Linvill, A. David, R. Kauffman, M. Futch, E.V. Arcos, J.M. Valenzuela, E. Martinot, M. Bazilian, and R.K. Pillai. 2015. Power Systems of the Future: A 21st Century Power Partnership Thought Leadership Report. Technical Report. Golden, CO: National Renewable Energy Laboratory. 53 pp. NREL/TP-6A20-62611. http://www.nrel.gov/docs/fy15osti/62611.pdf

Zinaman, O., M. Miller, and M. Bazilian. 2014. The Evolving Role of the Power Sector Regulator. Technical Report. Golden, CO: National Renewable Energy Laboratory. 18 pp. NREL/TP-6A20-61570. http://www.nrel.gov/docs/fy14osti/61570.pdf 


\title{
Appendix A. Electric Systems of the Future - Descriptions
}

\author{
Table A-1. Electricity Systems of the Future: Five Directions
}

\section{A. Business-As-Usual - A Baseline for Comparison \\ Non-transformational updates: replace aging infrastructure with current standard versions}

The main priorities are to keep utility accounting whole and secure financing to replace aging assets. "Least-cost" remains the most common decision metric. In 15-20 years, the maximum technology potential entails replacing aging assets with current standard versions of the technology that fit within existing state and federal policy boundaries (e.g. CA has a "no coal" policy, renewable mandates are included). Generation ("G"), transmission ("T"), and distribution ("D") technologies have improved (some efficiency improvements). In both vertically integrated and restructured markets, deployment beyond renewables and energy efficiency policies isn't expected.

\section{B. Low-Carbon, Centralized Generation $\square$}

Replace large, centralized, high-carbon generation with large, centralized, low-carbon generation

Existing generation is replaced with centralized, low-carbon generation (a. variable renewable energy, b. natural gas, c. clean coal and/or d. nuclear), resulting from carbon policies and/or an emphasis on lowest-risk metrics. In 15-20 years, central low-carbon generation $(G)$ begins to dominate and transmission $(T)$ interconnectivity and fidelity has substantially improved. A modernized (but not optimized) T grid, equipment, and communications technology increases flexibility. Financing availability is critical (rate base for T); no additional T-distribution (D) interactions. Retail markets are largely unchanged, but wholesale markets value carbon, grid flexibility services, and T efficiency. DG and consumer participation remains comparable to BAU. Lower carbon emissions result.

\section{Rapid Growth of Distributed Energy Resources (DER)}

Non-dispatchable distributed generation, distributed storage, and energy efficiency become common

Distributed energy resources (non-dispatchable distributed generation (DG) and distributed storage) benefit from new valuations, new requirements, and cost decreases. Modernization and optimization (2-way power flow, communications, IT) of the D grid is financed by mix of rate base and public sources of capital. Utility customers, DER developers, third-party owners, and electric utilities can value and benefit from distributed generation, energy efficiency, and new energy storage options. In deregulated markets, the operator of "wires" balance generation, storage, and demand and is supported by decoupling. In vertically integrated markets, the "Energy Services Utility" is incentivized to increase system flexibility to lower overall costs by providing energy services and efficiency to the end customer (not energy). Utilities may also own the DG and/or storage (more likely to own if the services are valued). Energy efficiency and grid services could become profit centers for the utility. Unclear carbon impact.

\section{Interactivity of the Grid and Demand $\square$}

Most flexible, integrated, and optimized T\&D, grid-level storage, dispatchable DG, demand response, smart grid, and consumers demand interactivity

The most flexible, integrated, and optimized transmission grid is linked with the optimized distribution grid, grid-level storage, dispatchable DG, smart grid, demand response, and consumer demand interactivity. T \& D systems are modernized enabling communication and improved management that includes between T and D. Both planning and operations are flexible and optimized. The role of end-use customers expands and they provide capital (or secure capital from financiers) for dispatchable DG, energy use scheduling through smart appliances, and increased demand through EVs. Customers (or their aggregators) have energy management systems that minimize cost while providing required services and that interact with their neighbors, the grid, or retail markets (potentially at all three levels). Retail customers actively participate in demand response programs and markets. Utility business models evolve to allow for this increased customer ownership and participation, while providing backup power to participants, reliable power to non-participants, and still being profitable. Utilities can value new services and have a more complex role in operations, communications, and coordination across regions/systems. Although utility-scale central generation still dominates in 20 years, DG penetration is enabled and thus, notable.

\section{E. Grid or Load Defection}

Dramatic improvements in storage, cost reductions in DG, and high-energy costs lead to defection

Utilities have trouble keeping pace with consumer demand for clean energy, DG, or both and could suffer the consequences: reduced or disconnected loads that could lead to stranded assets, uncertain and high financing costs, and decreasing customer base. Utilities struggle to find ways to get paid for services without causing more grid defection; and may institute large disconnection fees or standby charges. 


\section{Appendix B. Summary of Emerging Disruptions and How They Map to Potential Futures}

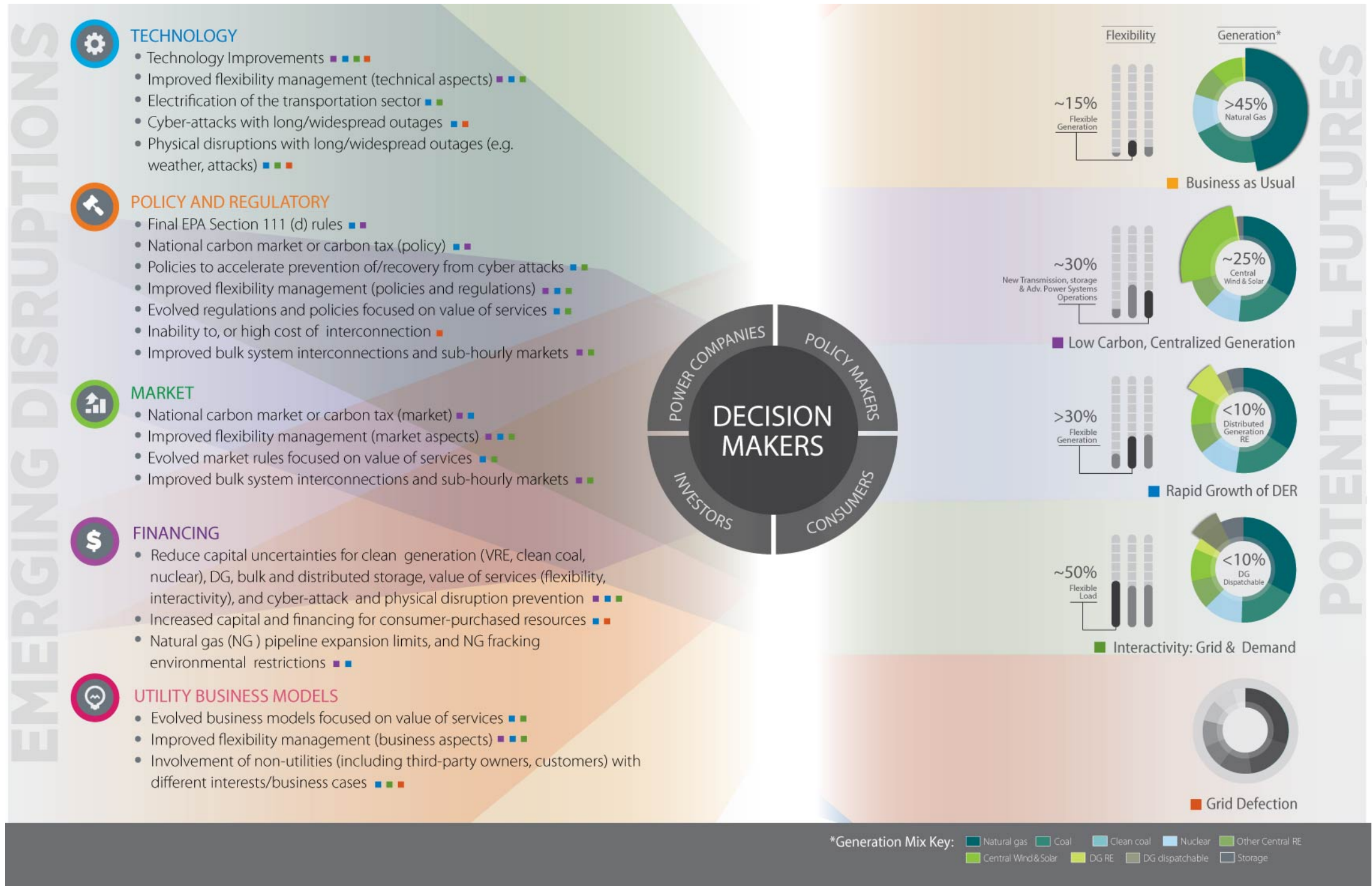

Figure B-1. Summary of emerging disruptions and how they map to potential futures

Note: Donut chart values are high-level approximations of the changing generation mix, depending on which future direction is enabled. The amount of change in the flexibility of the system is also approximated (bar chart). Detailed analysis should be performed at specific locations, as proposed in the Next Steps. 


\section{Appendix C. Key Enablers and Barriers for Three Main Future Directions}

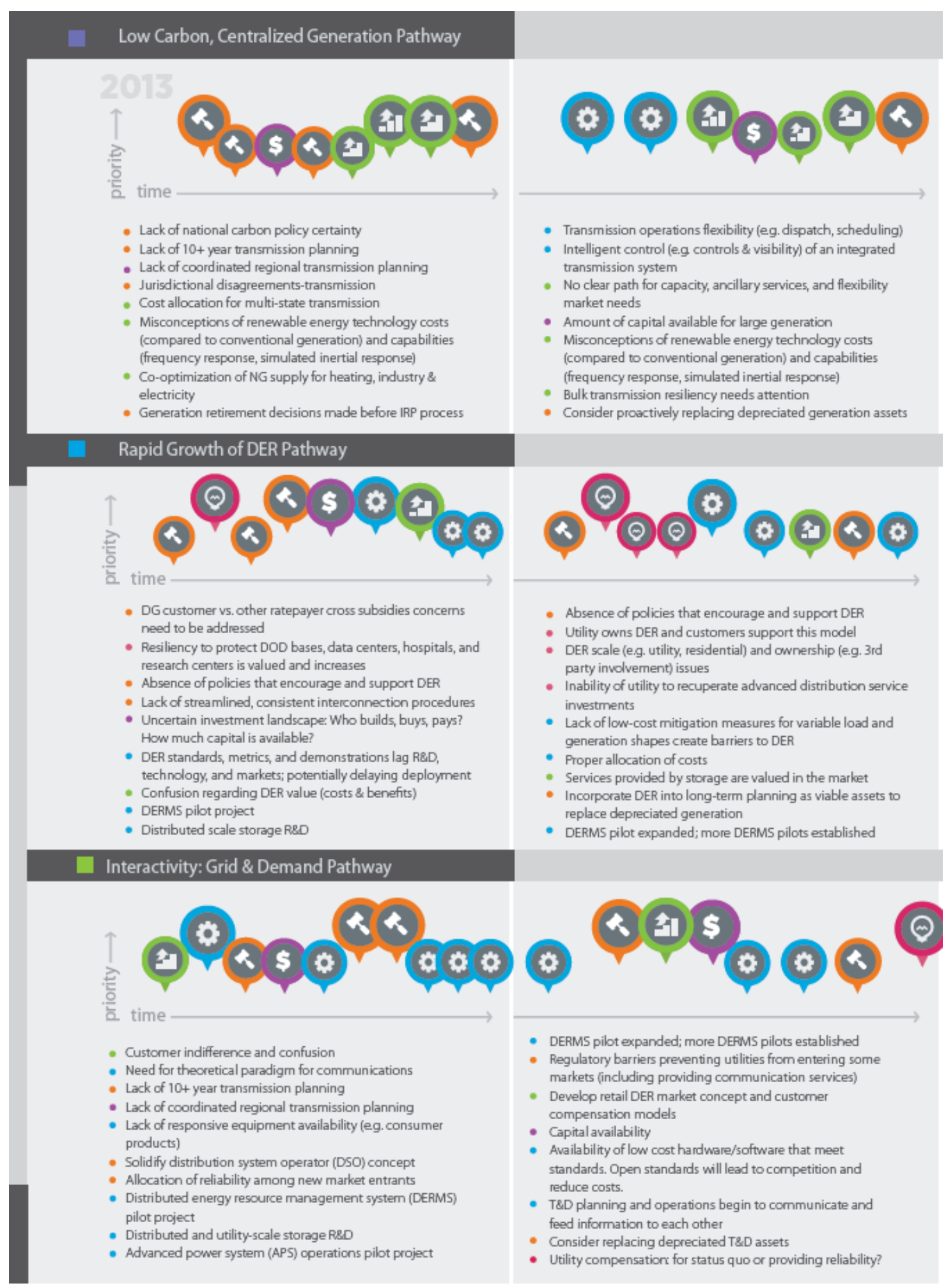

Figure C-1. Key enablers and barriers for three main future directions (the earlier years) 


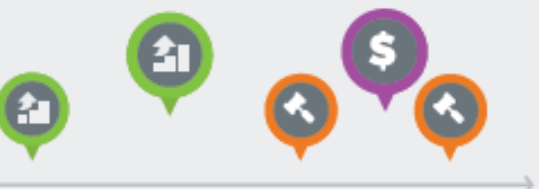

- Availability (including transmission, storage, markets, and traders) of natural gas

- Access to capacity and ancillary services markets

- Incorporation of emissions goals into Integrated Resource Planning (IRP) and regional G, T \& D planning

- Long-term revenue certainty and access to capital

- Generation retirements are competed in IRP on other long-term planning process
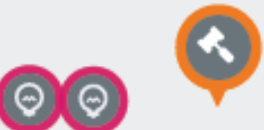

Flat or no electricity load growth

- No generation retirements

- Environmental constraints emerge (e.g. water availability for electricity generation)

- Misconceptions of renewable energy technology costs (compared to conventional generation) and capabilities (frequency response, simulated inertial response)

- Consider proactively replacing non-depreciated generation assets

- Capital availability

Rapid Growth of DER Pathway

\section{s (4) (4)

- Uncertainty leads to more costly financing and less capital

- Continuation of new communication and demonstration standards to encourage adoption of new technology and R\&D

- Need for safety crews and voltage control protection

- Inflexible distribution grid may limit DG integration and storage adoption

Value of and payment for utility services begins to be clarified

- Secure more certain and transparent approvals, policies, and regulations (e.g. regulatory approval) to increase DER projects deployed - in short term and long-term

- DER valued in markets

- Better metrics for risk management are needed

- Encouraged investment in pilot projects despite some risk of failure

- Value proposition of DER for consumers remains despite low electricity rates in some regions

- Potential for increasing stranded investments

- Lack of low-cost communication and controls at increasing levels of DER penetration

- Full DERMS deployment

- Storage is cost competitive and/or value is monetized in market

\section{Interactivity: Grid \& Demand Pathway}

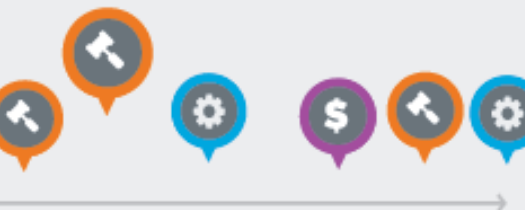

Implement DSO pilot projects

- Need for integrated transmission and distribution planning, as well as contemplating integrated cperations

- Full smart meter deployment

- Overall lack of financing availability could be limiting

- Generation and T\&D are competed against each other in IRP or other long-term planning process

- APS operations implementation ongoing

- Retail DER market "animated"

- Fully interactive DSO implemented

- DSO works in concert with RTOs/1SOs

- 3rd party barriers to entry may persist

- Full DERMS deployment

- Full APS deployance

- Consider proactively replacing non-depreciated TRD assets

- Capital availability

Figure C-2. Key enablers and barriers for three main future directions (the later years) 
The key barriers and enablers to each Electric System Future-1) low-carbon, centralized, 2) rapid distributed energy resource growth, and 3) interactivity of the grid and demand - are shown side-by-side, and sequenced across a 20-year time period (2015-2030's). By showing the pathways side by side, one can compare the key barriers and enablers that, if addressed, could best enable any one future, and across all futures.

In early stages these futures are each marked by different predominant types of barriers and enablers. Policy dominates the low carbon, centralized future followed by market considerations regarding transmission planning and technology costs. Utility business model and policy barriers and enablers are closely intertwined in early stages of the rapid DER growth future. Once these issues are overcome, and DERs expand, then more technology barriers and enablers arise. A host of technology considerations appear to be important in the early stages of the interactivity of the grid and demand future in order for it to be fully enabled. Financing barriers emerge in all three futures, and are particularly relevant to the DER future.

In the second stage, transmission-related barriers and enablers become more technical in nature and market questions linger in the low carbon, centralized future. Utility business model issues continue to be critical to this stage of rapid DER growth and technical barriers and enablers to interactivity of the grid and demand.

Further into the future (approximately 2025-2035, or stages three and four), experts envision fewer technical barriers, but more market and policy challenges in the low carbon, centralized future. For rapid DER growth, technical and utility business model barriers and enablers rise to the top at these later stages. While predominant in the early stages of interactivity of the grid and demand, technology barriers and enablers take a back seat to policy and market-related ones. Financing concerns remain throughout each future in these later stages as well.

Specific information regarding barriers and enablers of each future are presented in bullet points shown in the charts. Table $\mathrm{C}-1$ also explains what could happen if each of the futures comes to fruition. In reality, a hybrid between these futures would truly be realized; however these combinations of futures were not examined together. 
Table C-1. Description of the Evolution of Each Future, Identifying Key Enablers and Barriers

\begin{tabular}{|c|c|c|c|c|}
\hline & Stage 1 & Stage 2 & Stage 3 & Stage 4 \\
\hline $\begin{array}{l}\text { Low-carbon, } \\
\text { centralized } \\
\text { generation }\end{array}$ & $\begin{array}{l}\text { Misconceptions persist regarding } \\
\text { renewable energy technology costs } \\
\text { (compared to conventional } \\
\text { generation) and capabilities. } \\
\text { Certainty regarding EPA } 111 \text { (d) and } \\
\text { carbon policy enactment are major } \\
\text { drivers at this stage, particularly for } \\
\text { financing availability. Transmission } \\
\text { planning and optimization between } \\
\text { gas and electricity is needed. }\end{array}$ & $\begin{array}{l}\text { Technological and market } \\
\text { concerns regarding transmission } \\
\text { operations, flexibility, capacity, } \\
\text { and intelligent system controls } \\
\text { dominate this stage, while } \\
\text { misconceptions of renewable } \\
\text { energy technology costs and } \\
\text { capabilities (frequency response, } \\
\text { simulated inertial response) may } \\
\text { persist. }\end{array}$ & $\begin{array}{l}\text { Characterized by uncertain access } \\
\text { to markets, revenue streams, and } \\
\text { natural gas availability coupled } \\
\text { with decreasing or flat electricity } \\
\text { load growth. Emissions goals are } \\
\text { incorporated into planning. } \\
\text { Questions about renewable } \\
\text { energy tech. costs and capabilities } \\
\text { are reduced, but still exist, } \\
\text { especially as penetration } \\
\text { increases. }\end{array}$ & $\begin{array}{l}\text { Environmental constraints } \\
\text { like water scarcity emerge } \\
\text { and understanding of the } \\
\text { costs and capabilities of } \\
\text { renewable energy } \\
\text { technologies need } \\
\text { refinement as the system } \\
\text { reaches higher } \\
\text { penetrations. }\end{array}$ \\
\hline $\begin{array}{l}\text { Rapid DER } \\
\text { growth }\end{array}$ & $\begin{array}{l}\text { Challenges in this stage include an } \\
\text { uncertain investment landscape, } \\
\text { absence of DER-supportive policies, } \\
\text { continued confusion regarding DER } \\
\text { value, lack of coordinated } \\
\text { distribution planning, delays } \\
\text { adopting DER (both DG and storage) } \\
\text { standards and metrics, and need for } \\
\text { Distributed Energy Resource } \\
\text { Management Systems (DERMS). }\end{array}$ & $\begin{array}{l}\text { Whether utility-scale VRE or } \\
\text { residential DG dominates this } \\
\text { stage remains unclear and likely } \\
\text { will depend on how market rules } \\
\text { and regulations emerge. DER } \\
\text { may suffer without supportive } \\
\text { policies and proper cost } \\
\text { allocation. Technologies capable } \\
\text { of mitigating variable DER load } \\
\text { and generation shapes are } \\
\text { expected to emerge. }\end{array}$ & $\begin{array}{l}\text { Uncertain regulatory approval } \\
\text { may threaten affordability of } \\
\text { financing and availability of } \\
\text { capital, unless addressed. } \\
\text { Technology solutions help } \\
\text { overcome barriers to DG } \\
\text { integration, and distribution } \\
\text { planning. Value of utility services, } \\
\text { operations, and voltage control } \\
\text { are clarified, and communication } \\
\text { and demonstration standards are } \\
\text { piloted. }\end{array}$ & $\begin{array}{l}\text { Increasing levels of DER will } \\
\text { likely require enhanced, } \\
\text { affordable communication } \\
\text { and control technology as } \\
\text { well as appropriate } \\
\text { financing to reduce the risk } \\
\text { of stranded investments. } \\
\text { High penetration means } \\
\text { greater level of risk } \\
\text { management is needed. }\end{array}$ \\
\hline $\begin{array}{l}\text { Interactivity of } \\
\text { the grid and } \\
\text { demand }\end{array}$ & $\begin{array}{l}\text { Market, technology, and policy } \\
\text { concerns intersect to begin to } \\
\text { enable an integrated, } \\
\text { communicative T, as well as D } \\
\text { energy software program. } \\
\text { Equipment may need to be } \\
\text { responsive and market entrants may } \\
\text { need to accept some burden of } \\
\text { system reliability. Whether } \\
\text { customers will respond with } \\
\text { confusion, indifference, or } \\
\text { acceptance to interactivity remains } \\
\text { to be seen. }\end{array}$ & $\begin{array}{l}\text { Distribution operator and } \\
\text { management systems are } \\
\text { established, expanded, and } \\
\text { begin conversations with } \\
\text { transmission. A new retail DER } \\
\text { market concept emerges. } \\
\text { Demand response begins to } \\
\text { penetrate many U.S. electricity } \\
\text { markets. Technology enables a } \\
\text { "plug and play" environment, } \\
\text { but regulatory barriers may } \\
\text { prevent utilities from entering } \\
\text { these new markets and } \\
\text { providing services. }\end{array}$ & $\begin{array}{l}\text { Utility compensation uncertainties } \\
\text { may linger throughout this stage. } \\
\text { Integrated T\&D planning becomes } \\
\text { critical as distributed system } \\
\text { projects penetrate and technology } \\
\text { advances and expands. Demand } \\
\text { response and flexible generation } \\
\text { play a critical role. }\end{array}$ & $\begin{array}{l}\text { DER retail markets are } \\
\text { implemented and deployed. } \\
\text { Distributed energy operator } \\
\text { and management systems } \\
\text { are fully deployed and work } \\
\text { in concert with a vibrant } \\
\text { demand response market, } \\
\text { and an interactive } \\
\text { transmission market; 3rd } \\
\text { party entry barriers are still } \\
\text { possible. }\end{array}$ \\
\hline
\end{tabular}




\section{Bibliography: Other Activities Evaluating Changes to the Electric Sector}

Note: The citations listed in the bibliography below informed the background of this work. This is a complete list that was used as a basis for formulating the other appendices, including Appendix A. Electric Systems of the Future - Descriptions, Appendix B. Summary of Emerging Disruptions and How They Map to Potential Futures, and Appendix C. Key Enablers and Barriers for Three Main Future Directions.

Some of the citations listed below repeat with the reference section because they were used in the development of the materials, as well as directly in this report. They are not listed in alphabetical order; they are listed them in order of those that seemed particularly helpful or relevant to a topic. Having said that, all resources listed are helpful to readers interested in learning more about a particular topic.

\section{Evolution of the Electric System}

- Zinaman, O., M. Miller, A. Adil, D. Arent, J. Cochran, R. Vora, S. Aggarwal, M. Bipath, C. Linvill, A. David, R. Kauffman, M. Futch, E.V. Arcos, J.M. Valenzuela, E. Martinot, M. Bazilian, and R.K. Pillai. 2015. "Power Systems of the Future: A 21st Century Power Partnership Thought Leadership Report.” Technical Report. Golden, CO: National Renewable Energy Laboratory. 53 pp. NREL/TP-6A2062611. http://www.nrel.gov/docs/fy15osti/62611.pdf

- Commonwealth Scientific and Industrial Research Organisation (CSIRO). 2013. Change and Choice: The Future Grid Forum's Analysis of Australia's Potential Electricity Pathways to 2050. https://publications.csiro.au/rpr/download?pid=csiro:EP1312486\&dsid=DS13

- Richter, Mario. 2013. "Business Model Innovation for Sustainable Energy: German Utilities and Renewable Energy." Energy Policy 62:12261237. doi:10.1016/j.enpol.2013.05.038

- Solar Electric Power Association (SEPA). 2014. “A Blank Slate for a New Energy Market." The 51st State Challenge. http://www.sepa51.org/

- Satchwell, Andrew, Peter Cappers, Lisa Schwartz, and Emily Martin Fadrhonc. 2015. A Framework for Organizing Current and Future Electric Utility Regulatory and Business Models. Berkeley, CA: Lawrence Berkeley National Laboratory. LBNL181246. http://emp.lbl.gov/sites/all/files/lbnl-181246.pdf

- Greentech Media. 2015. "Evolution of the Grid Edge: Pathways to Transformation." Accessed July. http://www.greentechmedia.com/research/report/evolution-of-the-gridedge-pathways-to-transformation

\section{Implications of the Growth of DERs on Utility Business Models}

- Electric Power Research Institute (EPRI). 2015. “The Integrated Grid." http://integratedgrid.epri.com/ 
- Electric Power Research Institute (EPRI). 2014. The Integrated Grid: Realizing the Full Value of Central and Distributed Energy Resources. Concept paper. EPRI. 44 pp. http://www.eenews.net/assets/2014/02/10/document_cw 02.pdf

○ Electric Power Research Institute (EPRI). 2015. Integrated Grid Pilot Projects: Utility Scale Solar. EPRI. 6 pp. Accessed

Aug. http://www.epri.com/abstracts/Pages/ProductAbstract.aspx?ProductId $=0000$ $\underline{00003002005004}$

- Electric Power Research Institute (EPRI). 2015. The Integrated Grid: A BenefitCost Framework. EPRI. 184 pp. Accessed

Aug. http://www.epri.com/abstracts/Pages/ProductAbstract.aspx?ProductId $=000$ $\underline{000003002004878}$

- Kind, Peter. 2013. Disruptive Challenges: Financial Implications and Strategic Responses to a Changing Retail Electric Business. Prepared by Energy Infrastructure Advocates for Edison Electric

Institute. http://www.eei.org/ourissues/finance/documents/disruptivechallenges.pdf

- Bloomberg New Energy Finance. 2014. "Fight, Flight or Adapt: How are US Utilities Coping with Distributed PV?” New York, New York: BNEF US Solar Research Note. (By subscription.) http://about.bnef.com/

- Corneli, Steven. (undated). "Distributed Energy Resources and the 'Utility Death Spiral: What it is, Why it is happening, What to do (and not do) about it'." NRG Energy. 11 pp. http://www.jisea.org/pdfs/2014_annual_meeting_corneli.pdf

- GreenTech Media. "The Grid Edge: Grid Modernization in the Age of Distributed Generation." Available to members

at https://www.greentechmedia.com/research/report/smart-grid-market-researchsubscription

- Goldman, Charles A., Andrew Satchwell, Peter Cappers, and Ian M. Hoffman. 2013. "Utility Business Models in a Low Load Growth/High DG Future: Gazing into the Crystal Ball?" Presented at Committee on Regional Electric Power Cooperation (CREPC)/State-Provincial Steering Committee (SPSC) Meeting. Boise, ID, April 10, 2013. 49 pp. http://emp.lbl.gov/publications/utility-business-models-low-loadgrowthhigh-dg-future-gazing-crystal-ball

- Solar Electric Power Association (SEPA). Benchmarking Utility Organizational Structures: How Renewable Energy Is Reshaping the Utility Hierarchy. Available to members of SEPA. http://www.solarelectricpower.org/benchmarking-utilityorganizational-structures-how-renewable-energy-is-reshaping-the-utility-hierarchy.aspx

\section{Impact of Grid Defection}

- Barclays Credit Research. 2014. "The Solar Vortex: Credit Implications of Electric Grid Defection."

Webinar. https://www.fiasi.org/index.php?option=com_civicrm\&task=civicrm/event/inf o\&option $=$ com civicrm\&id $=124 \&$ snippet $=2$ 
- Bronski, P., J. Creyts, S. Doig, L. Guccione, J. Mandel, B. Rader, H. Tocco, H. Touati, M. Crowdis, J. Glassmire, P. Lilienthal, and D. Seif. 2015. "The Economics of Load Defection.” Rocky Mountain Institute. Accessed

July. http://www.rmi.org/electricity_load_defection

- $\quad$ Bronski, P., J. Creyts, L. Guccione, M. Madrazo, J. Mandel, B. Rader, D. Seif, P. Lilienthal, J. Glassmire, J. Abromowitz, M. Crowdis, J. Richardson, E. Schmitt, and H. Tocco. 2014. The Economics of Grid Defection: When and Where Distributed Solar Generation Plus Storage Competes with Traditional Utility Service. Rocky Mountain Institute. Accessed

April. http://www.rmi.org/PDF economics of grid defection full report

\section{Barriers and Opportunities to High Adoption of Variable Energy Resources}

- Hand, M.M., S. Baldwin, E. DeMeo, J.M. Reilly, T. Mai, D. Arent, G. Porro, M. Meshek, and D. Sandor. 2012. Renewable Electricity Futures Study (Entire Report). 4 vols. Golden, CO: National Renewable Energy Laboratory. NREL/TP-6A20-52409. Accessed Aug 2014. http://www.nrel.gov/analysis/re futures/

- Jones, L., ed. 2014. Renewable Energy Integration: Practical Management of Variability, Uncertainty, and Flexibility in Power Grids. Academic

Press. http://scitechconnect.elsevier.com/wpcontent/uploads/2014/06/Sample_FM_Renewable-Energy-Integration-2.pdf

- Blarke, M., and B. Jenkins. 2013. "SuperGrid or SmartGrid: Competing Strategies for Large-Scale Integration of Intermittent Renewables?” Energy Policy 58:381-390.

Accessed Aug 2014. doi:10.1016/j.enpol.2013.03.039

- Small, Forrest, and Lisa Frantzis. 2010. The 21st Century Electric Utility: Positioning for a Low-Carbon Future. Prepared by Navigant Consulting for Ceres. July 2010. http://www.ceres.org/resources/reports/the-21st-century-electric-utilitypositioning-for-a-low-carbon-future-1

- Denholm, P., R. Margolis, B. Palmintier, C. Barrows, E. Ibanez, L. Bird, and J. Zuboy. 2014. Methods for Analyzing the Benefits and Costs of Distributed Photovoltaic Generation to the U.S. Electric Utility System. Technical Report. Golden, CO: National Renewable Energy Laboratory. NREL/TP-6A2062447. http://www.nrel.gov/docs/fy14osti/62447.pdf

- Taylor, M., J. McLaren, K. Cory, T. Davidovich, J. Sterling, and M. Makhyoun, M. 2015. Value of Solar: Program Design and Implementation Considerations. Technical Report. Golden, CO: National Renewable Energy Laboratory. 84 pp.NREL/TP-6A2062361. http://www.nrel.gov/docs/fy15osti/62361.pdf

- Solar Electric Power Association. Unlocking Advanced Inverter Technology: Roadmap to a Future of Utility Engagement and Ownership. Available to members only. http://www.solarelectricpower.org/unlocking-advanced-inverter-functionality.aspx 
- Edge, Ryan, Mike Taylor, Nadav Enbar, and L. Rogers. 2014. Utility Strategies for Influencing the Locational Deployment of Distributed Solar. Solar Electric Power Association (SEPA) and Electric Power Research Institute (EPRI). https://www.solarelectricpower.org/media/224388/Locational-DeploymentExecutive-Summary-Final-10-3-14.pdf

\section{Regulatory Implications of Different Energy Futures}

- New York State Department of Public Service. 2015. "Reforming the Energy Vision." Staff

Report. http://www3.dps.ny.gov/W/PSCWeb.nsf/All/CC4F2EFA3A23551585257DEA00 7DCFE2?OpenDocument

- Hawaiian Public Utility Commission. 2014. Exhibit A: Commission's Inclinations on the Future of Hawaii's Electric Utilities. Accessed Feb 2015. http://puc.hawaii.gov/wpcontent/uploads/2014/04/Commissions-Inclinations.pdf

- Miller, Mackay, and Sadie Cox. 2014. Overview of Variable Renewable Energy Regulatory Issues. Technical Report. Golden, CO: National Renewable Energy Laboratory. NREL/TP-6A20-61350. http://www.nrel.gov/docs/fy14osti/61350.pdf

- Zinaman, O., M. Miller, and M. Bazilian. 2014. The Evolving Role of the Power Sector Regulator. Technical Report. Golden, CO: National Renewable Energy Laboratory. 18 pp. NREL/TP-6A20-61570. http://www.nrel.gov/docs/fy14osti/61570.pdf

- Aggarwal, S., and E. Burgess. 2014. New Regulatory Models. Prepared for the StateProvincial Steering Committee on Regional Electric Power Cooperation. March 2014. Accessed: Jan 2015. http://americaspowerplan.com/wpcontent/uploads/2014/03/NewRegulatoryModels.pdf

- Lehr, Ronald. 2013. New Utility Business Models: Utility and Regulatory Models for the Modern Era: America's Power Plan. http://americaspowerplan.com/wpcontent/uploads/2013/10/APP-UTILITIES.pdf 